\title{
2011s-65
}

\section{A Dynamic Duopoly Investment Game without Commitment under Uncertain Market Expansion}

Marcel Boyer, Pierre Lasserre, Michel Moreaux

\begin{tabular}{c}
\hline Série Scientifique \\
Scientific Series
\end{tabular}

\section{Montréal}

Octobre 2011

C 2011 Marcel Boyer, Pierre Lasserre, Michel Moreaux. Tous droits réservés. All rights reserved. Reproduction partielle permise avec citation du document source, incluant la notice (C).

Short sections may be quoted without explicit permission, if full credit, including (C) notice, is given to the source.
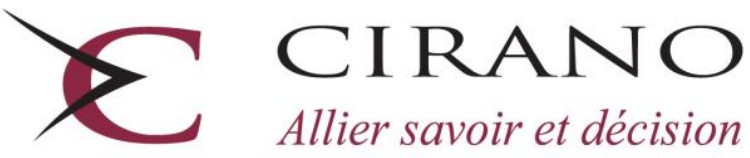

Allier savoir et décision

Centre interuniversitaire de recherche en analyse des organisations 


\section{CIRANO}

Le CIRANO est un organisme sans but lucratif constitué en vertu de la Loi des compagnies du Québec. Le financement de son infrastructure et de ses activités de recherche provient des cotisations de ses organisations-membres, d'une subvention d'infrastructure du Ministère du Développement économique et régional et de la Recherche, de même que des subventions et mandats obtenus par ses équipes de recherche.

CIRANO is a private non-profit organization incorporated under the Québec Companies Act. Its infrastructure and research activities are funded through fees paid by member organizations, an infrastructure grant from the Ministère du Développement économique et régional et de la Recherche, and grants and research mandates obtained by its research teams.

\section{Les partenaires du CIRANO}

\section{Partenaire majeur}

Ministère du Développement économique, de l'Innovation et de l'Exportation

\section{Partenaires corporatifs}

Autorité des marchés financiers

Banque de développement du Canada

Banque du Canada

Banque Laurentienne du Canada

Banque Nationale du Canada

Banque Royale du Canada

Banque Scotia

Bell Canada

BMO Groupe financier

Caisse de dépôt et placement du Québec

\section{CSST}

Fédération des caisses Desjardins du Québec

Financière Sun Life, Québec

Gaz Métro

Hydro-Québec

Industrie Canada

Investissements PSP

Ministère des Finances du Québec

Power Corporation du Canada

Rio Tinto Alcan

State Street Global Advisors

Transat A.T.

Ville de Montréal

\section{Partenaires universitaires}

École Polytechnique de Montréal

HEC Montréal

McGill University

Université Concordia

Université de Montréal

Université de Sherbrooke

Université du Québec

Université du Québec à Montréal

Université Laval

Le CIRANO collabore avec de nombreux centres et chaires de recherche universitaires dont on peut consulter la liste sur son site web.

Les cahiers de la série scientifique (CS) visent à rendre accessibles des résultats de recherche effectuée au CIRANO afin de susciter échanges et commentaires. Ces cahiers sont écrits dans le style des publications scientifiques. Les idées et les opinions émises sont sous l'unique responsabilité des auteurs et ne représentent pas nécessairement les positions du CIRANO ou de ses partenaires.

This paper presents research carried out at CIRANO and aims at encouraging discussion and comment. The observations and viewpoints expressed are the sole responsibility of the authors. They do not necessarily represent positions of CIRANO or its partners. 


\title{
A Dynamic Duopoly Investment Game without Commitment under Uncertain Market Expansion*
}

\author{
Marcel Boyer ${ }^{\dagger}$, Pierre Lasserre ${ }^{\ddagger}$, Michel Moreaux ${ }^{\S}$
}

\begin{abstract}
Résumé / Abstract
We model capacity-building investments in a homogeneous product duopoly facing uncertain demand growth. Capacity building is achieved through the addition of production units that are durable and lumpy and whose cost is irreversible. While building their capacity over time, firms compete à la Cournot in the product market given their installed capacity. There is no exogenous order of moves, no commitment regarding future decisions, and no finite horizon. We investigate Markov Perfect Equilibrium (MPE) paths of the investment game, which may include episodes during which firms invest at different times, a preemption pattern, and episodes in which firms invest simultaneously, a tacit collusion pattern. These episodes may alternate and are typically several. When firms have yet to invest in capacity, the sole pattern that is MPE-compatible is a preemption episode: firms invest at different times but have equal value. The first such investment may occur earlier and therefore be riskier than socially optimal. When both firms hold capacity, tacit collusion episodes may be MPEcompatible: firms invest simultaneously at a postponed time (hence holding back production in the meantime), thereby generating an investment wave in the industry. Such investment episodes are more likely with higher demand volatility, faster market growth, and lower cost of capital (discount rate).
\end{abstract}

Mots clés/Keywords : Real Options; Dynamic Duopoly; Lumpy Investments; Preemption; Investment Waves; Tacit Collusion.

Codes JEL : C73, D43, D92, L13.

\footnotetext{
*We are grateful to Thomas Mariotti, Bruno Versaevel, participants in conferences at Georgetown University and École des Dirigeants et Créateurs d'entreprises (EDC), in the Conference in honor of Claude Henry (Paris), as well as in seminars at USC, Penn State, UBC and UZH for their comments. Moreover, comments from two anonymous referees as well as the Editor were quite helpful in improving the paper. Financial support from CIRANO, CIREQ, SHRCC (Canada) and INRA (France) is gratefully acknowledged.

${ }^{\dagger}$ Bell Canada Emeritus Professor of Industrial Economics, Université de Montréal, marcel.boyer@umontreal.ca.

*Department of Economics, Université du Québec à Montréal, lasserre.pierre@ uqam.ca.

$\S$ Toulouse School of Economics at Université de Toulouse 1 Capitole, mmichel@cict.fr.
} 


\section{INTRODUCTION}

Investment games played by competing firms in oligopolistic markets typically share the following stylized characteristics: (i) the development of the market is uncertain, but firms have similar knowledge of the underlying random process generating the market development; (ii) firms' production capacities are built over time through additional units of significant size; (iii) investments in real assets are substantially irreversible; (iv) firms compete in the product market, given their installed production capacities, while they can at the same time develop those capacities; (v) any firm may invest at any time as the market develops and as its competitors build their own capacity; (vi) at the industry level, new investments sometimes come in waves with firms building new plants simultaneously and sometimes in sequences with firms investing at different dates; (vii) as the market matures, absent drastic innovations, capacity building eventually comes to an end determined by the potential market size, with capacities remaining essentially the same for an indefinite time.

We develop a duopoly model with features (i) to (v) above, which generates results (vi) and (vii) among others. More specifically, we consider a homogeneous product duopoly industry whose market demand is growing in a stochastic way. Firms compete continuously à la Cournot on the product market and they build up their capacity over time through the acquisition of lumpy units of capacity. There is no assumed or forced order of moves in capacity building, and no commitment on future investments or strategies. Rather, firms invest at chosen market development levels as they hold investment options to be exercised strategically at freely chosen

dates. We characterize the value of the investment options to be exercised at the chosen timings and the value of the firms holding them.

Investments are assumed irreversible and consist of indivisible capacity units that do not depreciate. Hence, capacity can only increase in discrete jumps. Market development is exogenous, stochastic, continuous, and its current level is observed by the duopolists. A state of the game is characterized by a triplet composed of the current demand level and each duopolist's installed capacity. In any given state, a firm may decide to invest or not in one or more additional units of capacity; hence, either both firms invest in one or more capacity units, only one firm does, or neither firm does. The timing of each investment is thus linked to the stochastic state of market development, thus is itself stochastic.

The present investment game is a dynamic game with no exogenously specified end. However it is not an 
infinitely repeated game as the continuation game is defined according to three state variables namely firms capacities and market size that are changing over time. We characterize the Markov Perfect Equilibria (MPE) of this investment game. A $M P E$ investment path takes the form of a sequence of investment decisions by each firm as the market evolves, while firms continuously compete day to day à la Cournot on the product market given their installed capacity and the attained level of demand.

Fudenberg and Tirole $(1983,1985)$ studied investment games involving a single investment by each player and found that two types of $M P E$ may exist. One involves simultaneous or joint investment, called tacit-collusion or under-investment equilibrium because the joint investment is postponed, meaning that the firms tacitly restrict their joint production capacity, thereby lessening the day to day Cournot competition. A second type of $M P E$ has investments occurring at different dates and was called a diffusion or preemption $M P E$ because they emerge from early move strategies aiming at preventing the other player from investing first. In a preemption $M P E$, industry capacity is larger, potential rents are dissipated, and firms obtain identical payoffs despite the asymmetry in the timing of their investments.

We consider an investment game involving multiple investments and admitting one or several investment paths as equilibria. In the investment game we develop and analyse in the present paper, $M P E$ investment paths will typically be composed of different episodes, each one starting from a state characterized by the current market development and the firms' installed capacities resulting from past decisions. Two types of episodes may appear along any given $M P E$ investment path: episodes during which firms invest at different times, in a preemption or intense competition mode, and episodes during which firms invest simultaneously, in a tacit collusion mode. When an episode along a MPE investment path has one firm investing earlier than the other, we say by analogy with the Fudenberg-Tirole's single-investment game that there is "preemption" during that episode, no matter what the sequence of previous or subsequent investments may be: rents are dissipated, and firms have identical incremental value. The first investment occurs precisely at the time when the market development level leaves the other firm indifferent between preempting or investing later: hence, no firm gains by moving first. When an episode along a $M P E$ investment path has both firms investing simultaneously, we say that there is "tacit collusion" during that episode. Indeed, such simultaneous investment takes place at a higher market development level, hence later, than the levels at which firms would invest if they were to invest at different times. Industry supply is then lower during the relevant market development interval than it would be otherwise, thereby generating tacit collusion rents for the firms: capacity building is postponed, production is lower, and prices and profits are increased relative to the 
levels that would prevail otherwise, that is, over the same market development interval if the firms were to invest at different times in a preemption episode. We characterize the factors and conditions for which along a given $M P E$ investment path one may encounter both preemption episodes and tacit-collusion ones. ${ }^{1}$

Our model is able to address the following questions at some level of generality: What is the link between the level of market or industry development and the intensity of competition? Do simultaneous investments or investment waves signal intense competition or tacit collusion? Can investments occur earlier than in perfect competition or in a social optimum? What is the role and effect of demand volatility, market growth rate, and cost of capital on the intensity of competition?

More precisely, our main results are as follows. If firms start from a symmetric position of zero capacity when the level of market development is low, the first $M P E$-compatible investment episode ${ }^{2}$ is necessarily a preemption episode, with only one active firm although both firms have necessarily the same value. Eventually the investment game will come to an end either with both firms having enough capacity to produce and sell the unconstrained Cournot quantity, if there is no tacit collusion at the end of the game, or both firms forever maintaining their capacities at a lower level, if the game ends with a tacit-collusion episode. Between the initial state of zero capacities with a low market development and the end of the game, two types of investment episodes may appear along any MPE path of the investment game. Starting in any state (market development level, installed capacities) in which further investment is profitable in the future for both firms, there exists a MPE-compatible preemption episode during which firms invest at different times. In some states, which we characterize, there exists also $M P E$-compatible tacit collusion episodes during which both firms invest at the same time. In MPE-compatible preemption episodes, incremental rents are equalized and partly dissipated. In MPE-compatible tacit collusion episodes, firms exercise market power by postponing their respective next investment until market development reaches a threshold that exceeds the level at which either firm would have invested in a preemption episode. Firms then invest simultaneously, thereby generating an investment wave in the industry. MPE-compatible tacit collusion episodes are typically several in a given state, which are all Pareto-superior from the firms' viewpoint to the $M P E$-compatible preemption episode in that given state. Furthermore, the market development trigger level at which the joint investment would maximize combined profits is MPE-compatible only if firms are of equal

\footnotetext{
${ }^{1}$ While there is a large literature on tacit collusion in infinitely repeated games, dynamic investment games are much less well understood. For example, it is well known that collusive equilibria exist in infinitely repeated games provided firms are sufficiently patient, that is, the discount factor is sufficiently large as shoiwn for instance in Dutta (1995a, 1995b). However, no such result exists in general for non repeated games.

${ }^{2}$ We use the terminology "MPE-compatible" to refer to an investment episode that is part of a $M P E$ investment path.
} 
size. Hence, when firms differ in size, tacit collusion falls short of maximizing combined profits. Nevertheless, an investment wave indicates that tacit collusion has occurred and has resulted in a successful exercise of market power. ${ }^{3}$ We show that higher market volatility, faster expected market growth, as well as lower cost of capital enlarge the set of conditions under which $M P E$-compatible tacit collusion episodes exist. However, no such $M P E-$ compatible tacit collusion episode exists in the early stages of market development, that is, when at least one firm holds no capacity.

Even though the investment game has no finite horizon, it eventually comes to an end at some stochastic time, that is, in a state from which no further investment is undertaken by the firms. We characterize these endgame conditions. This allows us to use backward induction to characterize the MPE-compatible investment sequences. As discussed further below, this result is closely dependent on the way we model market demand growth. If along a $M P E$-compatible investment sequence, a point is reached where endgame conditions are close to be met while firms have different capacities, then the smaller firm will be the sole investor for a while, possibly for the remainder of the game. Thus, while firms may be of different sizes along the equilibrium path, no size advantage can be maintained forever.

\section{The related literature}

The present paper extends the literature on strategic investment, most notably the seminal contributions of Gilbert and Harris (1984), Fudenberg and Tirole (1985), and the more recent contribution of Besanko and Doraszelski (2004), Genc et al. (2007), and Besanko et al. (2010). These contributions brought forward the analysis of the role of investment competition in shaping the structure of a developing industry, including rent equalization and dissipation in dynamic investment games, tacit collusion conditions in such games, and the durability of a first-mover advantage. Investigating the role of investment in acquiring market dominance in a very general framework, Athey and Schmutzler (2001) came to the conclusion that, without firms' commitment to future strategic investment plans, there is little hope to obtain definitive predictions outside specific models. In an effort to provide tractable results, modern investment games indeed were often modeled in a way that failed to exhibit some of the stylized facts mentioned above. Such models include models of technology adoption, models of entry, and numerous two-stage models where firms first make and commit to long-term decisions (stage

\footnotetext{
${ }^{3}$ Some authors found that investment waves sometimes indicate harsh preemptive competition, as for instance in a premptive race to acquire a dominant position. Here investment waves indicate tacit collusive behavior with both firms postponing their respective acquisition of capacity units, hence holding back production and raising prices and profits in the meantime.
} 
one) before competing in short-term decisions afterwards (stage two). Although the possibility of preemption and collusion equilibria has been widely described within two-stage games, ${ }^{4}$ such games cannot account for the possible succession of intensive competition (preemption) episodes and tacitly collusive episodes along a given MPE-compatible investment path.

Gilbert and Harris (1984) recognized early the role of lumpy, strategic investments in dynamic frameworks. Our endgame characterization (no size advantage can be maintained forever) is reminiscent of Gilbert and Harris (1984, Proposition 1) who find an open-loop Cournot-Nash equilibrium where capacities stay within one unit of each other during the whole duopoly development. However, when the commitment assumption that goes with open loop in their model is removed, a drastic change occurs: one firm builds all plants while the other builds none (Proposition 6). This result can be traced back to an ad hoc asymmetry that Guilbert and Harris introduce into their game formulation in order to be able to remove the commitment assumption. Fudenberg and Tirole (1985) provided the methodological tool for analyzing preemption and joint investment in continuous time with neither precommitment nor ad hoc asymmetry. We use their methodology, adapted to a continuous diffusion process.

Genc et al. used the concept of S-adapted open-loop equilibrium of Haurie and Zaccour (2005) to analyze different formulations of dynamic investment games. They showed in particular that more volatility in demand, providing higher profits for firms, could favor entry in the relevant markets. Besanko and Doraszelski (2004) developed a computational approach to study discrete dynamic investment games with a preemption race in the early stages followed by capacity coordination through capital depreciation in later stages. They show in particular that low product differentiation and low sunkness of investments favor such sequences of investments. An important characteristic of these works is the intended and successful application of the models to real industrial cases. Indeed, Besanko et al. (2010) wonder why “... some industries experience both preemption races and capacity coordination, (while) others seem to sidestep preemption races altogether." (p. 2). The comparison with our model is difficult since we have quantity competition and homogenous products while they have price competition and differentiated products; we have infinite Markovian dynamic market uncertainty while they have infinitely repeated independent draws; we have irreversible investment while they have some degree of reversibility. Their analysis and ours should be understood as first steps in identifying conditions under which

\footnotetext{
${ }^{4}$ Kreps \& Scheinkman (1983), Deneckere \& Kovenock (1996), Allen et al. (2000), and Mason and Weeds (2005), to name only a few.
} 
episodes of intense competition and episodes of tacit collusion may both be present and even alternate along an equilibrium sequence of industry investments.

Our model has some similarities with Nocke (2007)'s dynamic game of quality adoption. However, besides differences discussed by Nocke between quality investment games and capacity investment games, the main difference is that we study an industry under continuous stochastic development rather than an industry having reached a given level of development. As a result, investments are not concentrated in equilibrium at any single date or level of market development, but occur in episodes along an investment path. Competition intensity may vary over time as investments proceed along an equilibrium sequence. ${ }^{5}$

We show that the set of conditions under which tacit collusion episodes may exist along a $M P E$-compatible investment path is enlarged when the discount factor is larger (lower discount rate). This is a form of folk theorem which is reminiscent of but different from Dutta's theorem (1995a, 1995b) stating that, for sufficiently patient players, there exist a tacitly collusive MPE equilibrium, along which firms maximize their joint value. In our model, joint profit maximization can appear in $M P E$-compatible tacit collusion episodes. However, the investment game eventually comes to an end so that players loose their ability to punish deviant behavior and may not be able to benefit from being sufficiently patient as in Dutta. Consequently other considerations affecting the ability to punish deviations come into play. It turns out that joint value maximization is reachable only if firms are of equal size.

As mentioned above, firms hold investment options to be exercised strategically at dates to be chosen as the market develops. We value those investment options and the firms holding them. Those real option values are increased when market expected growth and volatility are higher. Remarkable progresses in the analysis of real option games have been realized and our paper is related to those developments. Among major contributors, Grenadier (1996) uses a game theoretic approach to determine the timing of options exercise in the real estate market; Smets (1995) provides a treatment of the duopoly in a multinational setup, which serves as a basis for the oligopoly discussion in Dixit and Pindyck (1994); Lambrecht and Perraudin (1996), Décamps and Mariotti (2004), and Pawlina and Kort (2006) investigate the impact of asymmetric cost on firms' investment strategies; Baldursson (1998) considers a duopoly model where firms make continuous incremental investments in capacity

\footnotetext{
${ }^{5}$ In the dynamic duopoly quality investment game of Nocke (2007), a state of the economy is characterized by the current pair of qualities detained by the firms; however, there is no change in the state of the market or the state of the technology. As a result, starting from any state of the industry, the equilibrium of the game is reached instantaneously. Timing is not an issue.
} 
showing that when firms differ in size initially, substantial time may pass until they are of the same size; Grenadier (2002) provides a general solution approach for deriving the equilibrium investment strategies of symmetric firms facing a sequence of investment opportunities with incremental capacity investments; Weeds (2002), Huisman (2001), Huisman and Kort (2003) study option games in a technology adoption context; Boyer et al. (2004) study a duopoly with multiple investments under Bertrand competition; Smit and Trigeorgis (2004) discuss different strategic competition models in the context of real options, while Chevalier-Roignant and Trigeorgis (2010) discuss option games. Boyer, Gravel and Lasserre (2011) review that literature.

The remainder of this paper is organized as follows. We present the model, the competition framework, the multiple unit lumpy investment game, and we characterize the endgame conditions in Section 2. We begin Section 3 with the explicit analysis of three different situations, each constituting a different game, that essentially envisage all relevant situations: no existing capacity; identical positive capacity levels; different positive capacity levels. We then combine these special cases in such a way that they correspond to alternative states in a single dynamic investment game. We complete with a discussion in Subsection 3.4 of the generality of our results and a discussion in Subsection 3.5 of their sensitivity to the choice of quantity rather than price as the strategic variable in the day to day competition on the product market. We conclude in Section 4. Detailed proofs are provided in the Appendix.

\section{THE MODEL}

\subsection{Industry characteristics}

We consider the development of an industry where demand is affected by multiplicative random shocks. The inverse demand function at time $t \geq 0$ is given by:

$$
P\left(Y_{t}, X_{t}\right)=Y_{t} D^{-1}\left(X_{t}\right),
$$

where $X_{t} \geq 0$ is aggregate output, $Y_{t} \geq 0$ is a random shock, and $D: \mathbb{R}_{+} \rightarrow \mathbb{R}_{+}$is the non-stochastic component of demand.

\section{Assumption 1}

Demand $D(\cdot)$ is strictly decreasing, continuously differentiable and integrable on $\mathbb{R}_{+}$, and $D(0)=\lim _{p \downarrow 0} D(p)<$ 
$\infty$; the mapping $x \mapsto x D^{-1}(x)$ is strictly concave on $(0, D(0))$; aggregate shocks $\left(Y_{t}\right)_{t \geq 0}$ follow a geometric Brownian motion:

$$
d Y_{t}=\alpha Y_{t} d t+\sigma Y_{t} d Z_{t}
$$

with $Y_{0}>0, \alpha>0, \sigma>0$, and $\left(Z_{t}\right)_{t \geq 0}$ a standard Brownian motion with respect to the complete probability space $(\Omega, \mathcal{F}, P)$.

Multiplicative separability of the inverse demand function is frequently used in dynamic competition models, with $D^{-1}$ referred to as the generic inverse demand. Nocke (2007) uses a unitary elastic version of it in a dynamic game of quality and capacity investment. Bayer (2007) uses another version in a duopoly model of investment timings where the function $D$ is reduced to four possible values implied by two alternative levels of capacity and two states of nature.

Our model involves a continuous and volatile market development that proceeds indefinitely. Since production cost is zero once the capacity is installed, there is a theoretical possibility for the price to become arbitrarily close to zero so that $D(0)$ becomes an important limiting case. We assume that $D(0)$ is finite: a good, even if it is free, is never consumed in infinite quantity. This assumption is compatible with any conventional demand specification such that quantity demanded is finite and constant at a zero price. Combined with multiplicative separability in (1) it is particularly adequate for endproducts whose market grows because of income growth, changes in tastes or technical progress, but not because of indefinite population increase. ${ }^{6}$ Indeed, multiplicative separability in (1) may then be interpreted as follows. The number of consumers, actual and potential, in the market remains constant as the market develops, while consumers' valuation of the good grows stochastically, say because their incomes stochastically change. However, if the product is available at zero price, the quantity demanded at that price would not change with changes in incomes. For example, internet demand expands over time, but internet use is limited by the finite number of hours that users can devote to it over a given period of time; one does not expect any growth in demand at zero price unless the number of consumers increases. Similarly, in the highly common cases where consumer revenue growth drives market expansion, one should expect demand to increase at all prices where the income constraint is binding and only at such price levels; this implies $\frac{\partial P\left(Y_{t}, X_{t}\right)}{\partial Y_{t}}>0$ when $P(.,)>$.0 and $\frac{\partial P\left(Y_{t}, X_{t}\right)}{\partial Y_{t}}=0$ when $P(.,)=$.0 which is satisfied if $P$ is given by (1) with $D(0)<\infty$. Consumers

\footnotetext{
${ }^{6}$ Population increase would give rise to replication economies proportional to population size as it is often assumed in studies of asymptotic properties of oligopoly models.
} 
might purchase more bicycles more often as the rise in their revenues allows them to acquire the latest models and to own, say, one bike for each specialty; this is precisely what should be expected from the income effect in case of a drop in price. But when the price is zero the income effect vanishes. ${ }^{7}$

Expression (1) combined with Assumption 1 also allows cycles and phases of positive and negative growth before a market reaches maturity. As will be shown shortly, it is also most useful in the derivation of endgame conditions for the investment game to come to an end.

Firms are risk neutral and discount future revenues at the same rate $r>\alpha$. Investment takes place in a lumpy way. Each capacity unit costs $I$, which is constant over time, produces at most $Q=1$ unit of output, does not depreciate, and has no resale value. Given the normalization $Q=1$, the lumpiness of capacity units will be reflected in the size of generic demand. That is the smaller $D($.$) , the lumpier investment is in the sense that, at$ any given price, the demand will be satisfied by a smaller number of capacity units. Similarly, the unconstrained Cournot output can be achieved with a variable number of capacity units depending on the size of generic demand.

\subsection{Competition, output, and investment}

We consider a duopoly. In Boyer et al. (2004) we studied a related preemption model with instantaneous competition in prices (Bertrand) and where each firm may invest at most once. Here, firms make as many investments as they wish at dates that they choose, while continuously competing in quantities (à la Cournot), subject to capacity constraints. Specifically, within the interval $[t, t+d t]$, the timing of the game is as follows: (i) first, each firm $f$ chooses how many capacity units $\nu_{t}^{f}$ to invest in, given the realization of the demand shock $Y_{t}$ and the existing capital stocks $\left(k_{t}^{f}, k_{t}^{-f}\right)$; (ii) next, each firm selects an output level within its capacity, $x_{t}^{f} \leq k_{t}^{f}+\nu_{t}^{f}$; (iii) last, market price is determined according to (1), with $X_{t}=x_{t}^{f}+x_{t}^{-f}$.

The specification of inverse demand (1) implies that the short-run Cournot quantities are independent of the realization of the current industry-wide shock. We can assume that, in the absence of capacity constraints, this game has a unique equilibrium $\left(x^{c}, x^{c}\right)$. Let $k^{c}=\left\lceil x^{c}\right\rceil$ be the minimum capital stock required to produce $x^{c}$. It is

\footnotetext{
${ }^{7}$ In contrast if market development results from an increase in the number of consumers, this formulation is less adequate as $D(0)$ should reflect the evolving number of potential buyers. It would be possible to formulate in that case a version of (1) if the number of potential buyers (the population) were limited by an upper bound. Similarly if the good is an intermediate good or is complementary to some other good, the assumption implied by (1) is at best an approximation. For example, while water as an endproduct fits the model nicely, water as a complementary good whose demand reflects the number of swimming pools does not satisfy the assumption that $\frac{\partial P\left(Y_{t}, X_{t}\right)}{\partial Y_{t}}=0$ when $P(.,)=$.0 implied by (1). It would be possible to formulate a more general version of (1) such that market shocks would not affect quantity demanded at a zero price when the prices of the relevant complementary goods are all zero.
} 
then easy to check that, with given capacities $k^{f} \leq k^{-f}$, only three Cournot equilibrium outcomes can occur: (i) both firms are constrained, so that $x^{f}=k^{f}$ and $x^{-f}=k^{-f}$; (ii) the smaller firm is constrained, so that $x^{f}=k^{f}$, while the bigger firm is not and reacts optimally by choosing $x^{-f}$ on its reaction function; (iii) both firms are unconstrained, so that $x^{f}=x^{-f}=x^{c}$. The corresponding instantaneous profit of a firm with capacity $k$ when its competitor holds $\ell$ capacity units can be conveniently denoted $Y_{t} \pi_{k \ell}$, where $\pi_{k \ell}$ depends on capacities only. The explicit treatment of Cournot competition not only makes the analysis more transparent; it also gives economic foundation to payoff values that are crucial to the solution of the game and would otherwise appear as ad hoc assumptions.

\subsection{Markov strategies}

A key assumption of our model is that firms cannot (credibly) commit to future investment and output decisions. The game typically generates several investments occurring at endogenous (stochastic) dates. There is no commitment by the firms with respect to their role as first or second mover (the order is endogenous) or to the number of units they will acquire. The natural equilibrium concept here is the Markov perfect equilibrium $(M P E)$, in which firms' investment and output decisions at each date depend only on the firms' capital stocks measured in capacity units $\left(k^{f}, k^{-f}\right)$ and the current level of the industry-wide shock $y$. This rules out implicit collusion between firms when deciding on output: at each date, and given their current capacities, firms play the unique equilibrium of the static Cournot game described above.

In situations where two pure-strategy equilibria exist, where either firm invests first and the other firm second, for identical payoffs, there is a possibility, if firms use pure strategies, that both firms invest simultaneously by mistake. Fudenberg and Tirole (1985)'s concept of mixed strategies for timing games in continuous time avoids this sort of coordination failure. They focus on deterministic environments, while we consider stochastic demand. The basic idea is to construct a continuous-time representation of limits of discrete-time mixed-strategy equilibria by defining a strategy for firm $f$ as a function $s^{f}$ specifying the intensity $s_{\nu^{f}}^{f}\left(k^{f}, k^{-f}, y\right) \in[0,1]$ with which firm $f$ invests in $\nu^{f}$ capacity units given the capital stocks $\left(k^{f}, k^{-f}\right)$ and the industry-wide shock $Y_{t}=y$. A detailed treatment can be found in Boyer et al. (2004, Appendix A). In the rest of the paper, we will omit firm and strategy profile indices in the expression of value functions when no ambiguity arises. 


\subsection{Firm valuation}

Since $\left(Y_{t}\right)_{t \geq 0}$ is a time homogeneous Markov process, an outcome may be described as an ordered sequence of investment triggers together with the short-run instantaneous profits of both firms $Y_{t} \pi_{k l}$ and $Y_{t} \pi_{l k}$ between investments. Let $y_{i j}$, where $i$ and $j$ refers to the firms' capacities immediately before $Y_{t}$ reaches $y_{i j}$ for the first time, denote the value of $Y_{t}$ that triggers a new investment when total industry capacity is $i+j$. Note that $y_{i j}=y_{j i}$. Indeed, by definition, the short-run instantaneous profits of the firms are $Y_{t} \pi_{i j}$ and $Y_{t} \pi_{j i}$ immediately before the investment; suppose that the firm of capacity $i$ invests at $y_{i j}$ while the firm of capacity $j$ abstains; then, whether the trigger is denoted $y_{i j}$ or $y_{j i}$, the short-run instantaneous profit of the firm of capacity $i$ is $Y_{t} \pi_{i+1, j}$ immediately after the investment while the short-run instantaneous profit of the firm of capacity $j$ becomes $Y_{t} \pi_{j, i+1} \cdot{ }^{8}$

Since capacity units do not depreciate, higher triggers along a given investment sequence correspond to higher industry capacity levels: along a given sequence, $y_{i j} \leq y_{k \ell} \Leftrightarrow i+j \leq k+\ell .^{9}$ If the game is over, then, by convention, $y_{i j}=\infty$.

Let us consider, for simplicity, investments of one capacity unit only $(\nu=1)$, as investments in multiple capacity units can be treated as one-unit investments occurring at the same time. Suppose $Y_{t}=y$; let $L(i, j, y)$ denote the current value of the firm of capacity $i$ if it carries out an investment immediately, while its opponent has capacity $j$. Let $F(i, j, y)$ be the current value of the firm of capacity $i$ when its competitor with capacity $j$ carries out an investment immediately. Let $S(i, j, y)$ denote the current value of the firm of capacity $i$, with its competitor holding capacity $j$, if both firms make a simultaneous investment at some future date, say when $Y_{t}$ reaches $y_{i j}$.

The following lemma gives analytical expressions for the $L, F$, and $S$ functions. The expressions are divided into a first part corresponding to the current investment and a second part corresponding to the continuation of the game. The latter part is not fully specified at this stage; it will be determined recursively by backward

\footnotetext{
${ }^{8}$ The level of market development that triggers a new investment at any given industry capacity in general differs from one investment sequence to another. Denote $y_{i j}^{1}$ the trigger corresponding to sequence 1 that has the firm of capacity $i$ invest and the other abstain; similarly denote $y_{i j}^{2}$ the trigger corresponding to sequence 2 where the firm of capacity $j$ invests while the firm of capacity $i$ waits. In general $y_{i j}^{1} \neq y_{i j}^{2}$; furthermore there may exist a $M P E$ admitting sequence 1 as an episode while sequence 2 may not be $M P E$-compatible.

${ }^{9}$ Clearly, no such restriction applies to alternative investment sequences: in the example of Footnote 7 , not only $y_{i j}^{1}$ may differ from $y_{i j}^{2}$ but $y_{i, j+1}^{1}$ may be lower than $y_{i j}^{2}$ despite the fact that industry capacity is higher in the first instance than in the second one.
} 
induction, starting from the 'horizon', defined in state space as the first (stochastic) time a situation (a capacity combination) is reached such that no more investment will ever take place.

Lemma 1 Let $Y_{t}=y$. The value of the firm of capacity $i$, when it invests immediately while the firm of capacity $j$ does not, is given by the following, where $k=i+1$ :

$$
L(i, j, y)=\frac{\pi_{k j}}{r-\alpha} y-I+\left(\frac{y}{y_{k j}}\right)^{\beta}\left[c\left(k, j, y_{k j}\right)-\frac{\pi_{k j}}{r-\alpha} y_{k j}\right]
$$

where $\beta=\frac{1}{2}-\alpha / \sigma^{2}+\sqrt{\left(\alpha / \sigma^{2}-\frac{1}{2}\right)^{2}+2 r / \sigma^{2}}>1$ and $c(k, j, y)$ is the continuation value of the same firm at the time of the next industry investment, if any (if $y_{k j}$ is finite).

Its value, when it stays put while its competitor of capacity $j$ invests now, is given by the following, where $\ell=j+1:$

$$
F(i, j, y)=\frac{\pi_{i \ell}}{r-\alpha} y+\left(\frac{y}{y_{i \ell}}\right)^{\beta}\left[c\left(i, \ell, y_{i \ell}\right)-\frac{\pi_{i \ell}}{r-\alpha} y_{i \ell}\right]
$$

Its value, when both firms invest simultaneously at some future trigger value $y_{i j}$, is given by the following, where $k=i+1$ and $\ell=j+1$ :

$$
S(i, j, y)=\frac{\pi_{i j}}{r-\alpha} y+\left(\frac{y}{y_{i j}}\right)^{\beta}\left(\frac{\pi_{k \ell}-\pi_{i j}}{r-\alpha} y_{i j}-I\right)+\left(\frac{y}{y_{k \ell}}\right)^{\beta}\left[c\left(k, l, y_{k \ell}\right)-\frac{\pi_{k \ell}}{r-\alpha} y_{k \ell}\right]
$$

Consider the expression for $L(i, j, y)$. The first part $\frac{\pi_{k j}}{r-\alpha} y-I$ gives the expected net present value of the profit flows achieved by increasing capacity from $i$ to $k=i+1$ at a cost of $I$, assuming that no more investment is made. The second part $\left(\frac{y}{y_{k j}}\right)^{\beta}\left[c\left(k, j, y_{k j}\right)-\frac{\pi_{k j}}{r-\alpha} y_{k j}\right]$ adjusts the first one for the effect of subsequent investments, that is for the (equilibrium) exercise by both firms of their investment options. Indeed, $\left(\frac{y}{y_{i j}}\right)^{\beta}$ may be viewed as a discount factor defined in state space rather than in time space. It is the expected discounted value, measured at $Y_{t}=y$, of receiving one unit of money when $Y_{t}$ will reach $y_{i j}$ for the first time. If market volatility is negligible $(\sigma \rightarrow 0)$, then $\beta \rightarrow \frac{r}{\alpha}$ and $\left(\frac{y}{y_{i j}}\right)^{\beta} \rightarrow e^{-r\left(t\left(y_{i j}\right)-t\right)}$ where $t\left(y_{i j}\right)$ is the time at which $Y_{t}$ will reach $y_{i j}$. The function $c\left(k, j, y_{k j}\right)$ is the continuation value function when $Y_{t}=y_{k j}$. The expressions for $F(i, j, y)$ and $S(i, j, y)$ can be similarly understood. 


\subsection{Endgame conditions}

Although the investment game imposes no restrictions on capacities, we can characterize endgame conditions: the investment game is over if and only if it is known with certainty that no firm will ever invest in additional capacity. The following proposition gives two conditions, one necessary, one sufficient, for the investment game to be over (recall that capacity units do not depreciate).

Proposition 1 The investment game is over only if (necessity) either condition A or condition B is satisfied, implying that both firms hold a strictly positive capacity; moreover, the investment game is over if (sufficiency) Condition A is satisfied:

A Neither capacity constraint is binding in the short-run Cournot game, that is, $k^{f} \geq k^{c}=\min \left\{k \in \mathbb{N} \mid k \geq x^{c}\right\}, f \in\{1,2\}$.

$B$ Both capacity constraints are binding in the short-run game and would remain binding in case of a unit investment by any one firm.

Proposition 1 indicates (i) that no firm can keep its opponent out of the market in the long-run, and (ii) that a firm cannot use excess capacity in order to maintain a dominant position in the long-run. Condition $A$ falls short of implying equal capacities for both firms. However, it implies that, if capacities are not equal at the end of the game, the number of units used by each firm is the same. If capacities are not equal, some capacity is idle.

Condition $A$ says that the game is over if no firm experiences a capacity constraint in the choice of its Cournot output; since the duopoly game is time independent, this situation will not change as $Y_{t}$ evolves over time, so that no further investment is called for. Condition $A$ is not necessary, however. But if it is not satisfied at the end of the game, condition $B$ must hold. The latter condition pertains to tacit collusion. It describes a situation where each firm could still profitably increase its capacity if its rival did not react. For such a situation to last forever (game over), it must be the case that firms restrict capacity, hence output, in equilibrium. This implies that any deviation will be adequately punished. Condition $B$ describes a situation where a firm can inflict a punishment on its competitor if the latter deviates. If the former firm were no longer capacity constrained following an investment by its opponent (Condition $B$ not satisfied), then it would not be able to retaliate. Consequently, the (capacity constrained) opponent would invest whenever the level of market development would be adequate, 
without considering a potential reaction by its competitor.

The mere ability to retaliate is not sufficient to sustain a tacit collusion equilibrium. We characterize below the conditions under which the retaliatory power is sufficient to offset the gain from deviating. If the firm to be punished is small, it does not lose as much from an increase in the capacity of its opponent as if it were bigger. This implies that retaliation, hence collusion, is likely to be easier between firms of similar size, while this explains also why the investment game cannot be over unless both firms hold strictly positive capacities.

In what follows, firm asymmetry can only take the form of differences in current capacities and may be thought of as inherited from past moves in the industry development game. As discussed above, Lemma 1 provides only a partial characterization of value functions under alternative investment strategies. Completing the characterization requires knowledge of the continuation function $c(\cdot)$ and the appropriate trigger values. These can be determined when the game between the two firms is sufficiently near its end, in the sense of Proposition 1. Once the continuation value function is known in such situations, it is possible to characterize recursively the value function corresponding to the previous steps.

\section{INDUSTRY DEVELOPMENT}

Assuming multiplicative demand separability and a finite $D(0)$ guarantees that a finite number of capacity units are eventually installed so that the investment game eventually comes to an end. Industry development possibilities are represented in Figure 1 as a tree whose nodes give the number of units held by firms.

In order to investigate the level of competition at various points along an equilibrium path, it will be useful to focus on time intervals (or market development intervals) during which both firms invest once, either at the same time or at different times. In order to facilitate the analysis, we start with a series of simplified games designed in such a way that their solution is easily found; we then move on to the characterization of the general solution of the complete game by backward induction. 


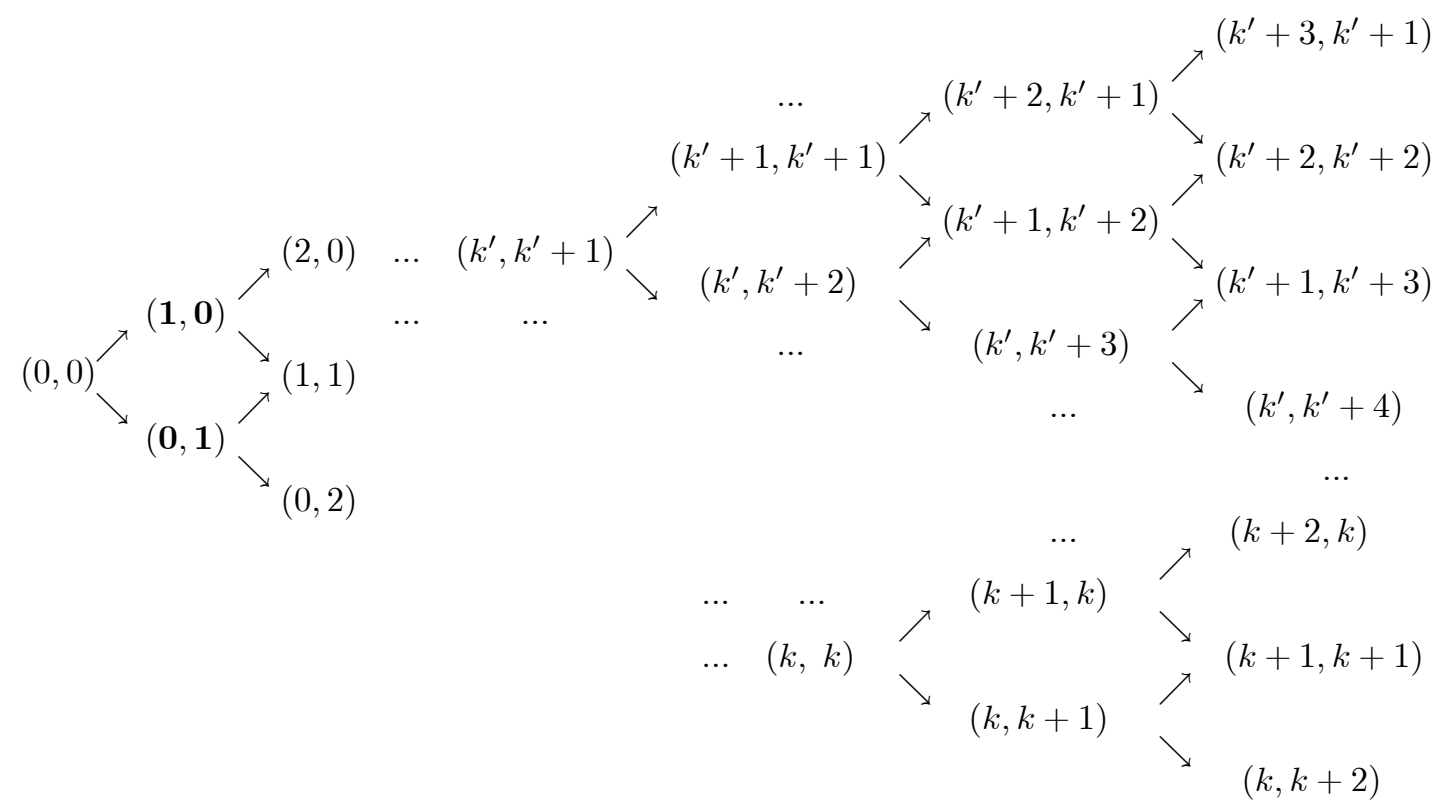

Figure 1: Industry capacity development tree

While the figure indicates the possible investment sequences, it does not show any timing, or the market development thresholds at which capacity nodes may be reached.

We characterize the capacity acquisition and the competition intensity prevailing at various stages (called episodes of capacity acquisition) of industry development: first, in the early stage when firms hold no capacity (Case 1); second, at a later stage, when firms hold similar (Case 2) or different (Case 3) capacities due to the unraveling of their respective investment strategies.

Each of these cases is first examined under a choice of demand parameters such that the end of the game is "near". By this we mean that demand assumptions ensure that, from the initial capacity nodes considered, a limited number of investments will lead to a situation where the investment game is over by Proposition 1 . Once these particular games are solved, a slight relaxation of the demand assumptions used in cases 1-3 allows us to consider them as continuations of more general investment games whose solution can then be obtained by backward induction. This allows us to generalize the analysis (in Subsection 3.4) to arbitrary nodes in the industry development tree. 


\subsection{Case 1: No existing capacity}

We start with a situation where initial capacities are zero. Let us assume generic demand to be such that unconstrained firms would produce at most one unit each in Cournot duopoly (recall Subsection 2.2), that is:

Assumption $20<x^{c} \leq 1$.

This assumption indicates that, although no firm holds capacity, we are close to the end of the investment game. It allows the monopoly output to exceed unity, so that the acquisition of more than one unit may be considered by any one firm, but it also implies that, if both firms hold one unit or more, the investment game is over by Proposition 1. Assumption 2 also implies that, whatever the (strictly) positive number of capacity units held by its opponent, a firm obtains instantaneous profit $Y_{t} \pi_{11}$ once it invests in one unit or more; consequently, it will not acquire more than one unit if its opponent holds positive capacity.

Therefore, the payoff from not investing immediately is (with $\pi_{1 \nu}=\pi_{11}$ by Assumption 2)

$$
F(0,0, y)=\left(\frac{y}{y_{0 \nu}}\right)^{\beta}\left(\frac{\pi_{11}}{r-\alpha} y_{0 \nu}-I\right)
$$

where $\nu$ is the number of units acquired by the opponent before the firm acquires its first and single unit. The stopping problem faced by the firm is then:

$$
F^{*}(0,0, y)=\sup _{y_{0 \nu}}\left[\left(\frac{y}{y_{0 \nu}}\right)^{\beta}\left(\frac{\pi_{11}}{r-\alpha} y_{0 \nu}-I\right)\right]
$$

with solution:

$$
y_{0 \nu}^{*}=y_{01}^{*}=\frac{r-\alpha}{\pi_{11}} I \frac{\beta}{\beta-1}, \quad \forall \nu \geq 1
$$

Knowing this, the value for the competitor of acquiring at least one unit immediately at $Y_{t}=y$, and any number of additional units before $Y$ reaches the threshold $y_{01}^{*}$ can be computed explicitly. For example, if it 
acquires one unit immediately and abstains from any further investment, its value is, according to Lemma $1:^{10}$

$$
L(0,0, y)=\frac{\pi_{10}}{r-\alpha} y-I+\left(\frac{y}{y_{01}^{*}}\right)^{\beta} \frac{\pi_{11}-\pi_{10}}{r-\alpha} y_{01}^{*}, \quad y<y_{01}^{*}
$$

where $\frac{\pi_{11}}{r-\alpha} y_{01}^{*}=c(1,0, y)$, since no more investment is forthcoming beyond $y_{01}^{*}$ by Proposition 1 . Similarly, if the investment in the first unit is to take place in the future at $y_{00}>y$, then the value of the firm is:

$$
L(0,0, y)=\left(\frac{y}{y_{00}}\right)^{\beta}\left(\frac{\pi_{10}}{r-\alpha} y_{00}-I\right)+\left(\frac{y}{y_{01}^{*}}\right)^{\beta}\left(\frac{\pi_{11}-\pi_{10}}{r-\alpha} y_{01}^{*}\right)
$$

Its maximum $L^{*}(0,0, y)$ with respect to $y_{00}$ is reached at:

$$
y_{00}^{L}=\frac{r-\alpha}{\pi_{10}} I \frac{\beta}{\beta-1} .
$$

Figure 2 illustrates the functions $L(0,0, y), L^{*}(0,0, y)$ and $F^{*}(0,0, y)$.

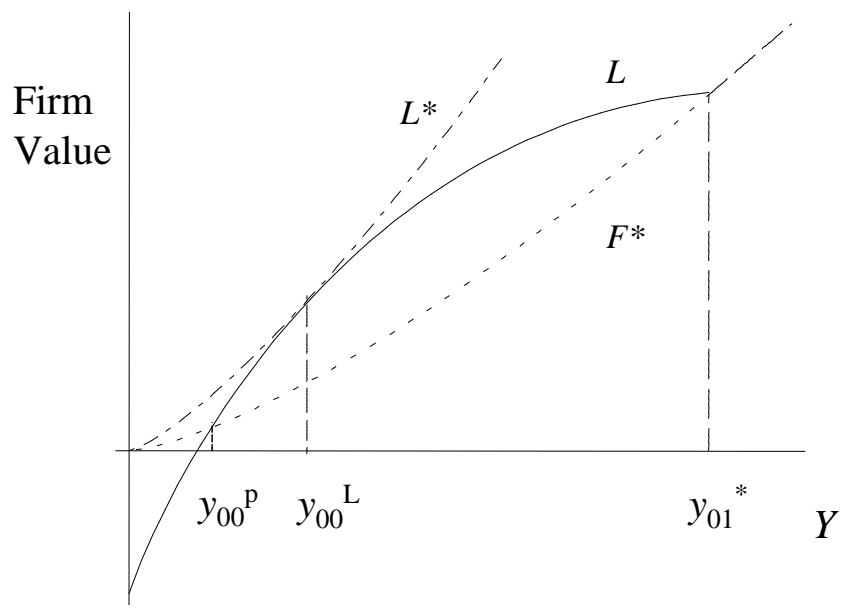

Figure 2: Firm values under alternative strategies

It is straightforward to check from (3)-(6) that, within the interval $\left(0, y_{01}^{*}\right)$, there exists a unique value $y_{00}^{p}$, corresponding to the intersection of $F^{*}$ with $L$ in Figure 2, such that for $y<[>,=] y_{00}^{p}, L(0,0, y)<$ $[>,=] F^{*}(0,0, y)$; the corresponding stochastic stopping time is $\tau_{00}^{p}=\inf \left\{t \geq 0 \mid Y_{t} \geq y_{00}^{p}\right\}$.

\footnotetext{
${ }^{10} \mathrm{We}$ leave it to the reader to adapt the formula and the rest of the argument for any number of units acquired by the first investor before the other one invests at $y_{01}^{*}$. For example, if the firm plans to acquire a second new unit at some $y^{\prime}, y \leq y^{\prime}<y_{01}^{*}$, the candidate value for $L(0,0, y)$ is $\frac{\pi_{10}}{r-\alpha} y-I+\left(\frac{y}{y^{\prime}}\right)^{\beta}\left[\frac{\pi_{20}-\pi_{10}}{r-\alpha} y^{\prime}-I\right]+\left(\frac{y}{y_{01}^{*}}\right)^{\beta} \frac{\pi_{21}-\pi_{20}}{r-\alpha} y_{01}^{*}, \quad y \leq y^{\prime}<y_{01}^{*}$ where $\pi_{21}=\pi_{11}$ by Assumption 2 . If this value is higher than (5), then it gives the correct expression for $L(0,0, y)$; if it is lower, then (5) is the appropriate expression. Note that the number of candidates to try is low as it cannot exceed the monopoly capacity under Assumption 2.
} 
We now determine the firms' equilibrium strategies before any firm has invested, that is, in states of the form $(0,0, y)$. If $y<y_{00}^{p}$, investing is for both firms a strictly dominated strategy while, for $y \geq y_{01}^{*}$, delaying investment any further is also a strictly dominated strategy. To determine the equilibrium outcome when $y_{00}^{p} \leq y<y_{01}^{*}$, it is helpful to consider what would happen if one of the firms were protected from preemption and could thus choose its optimal stand-alone investment date as a monopoly. Given a current industry-wide shock $y$, the maximal expected payoff that this firm could then achieve by taking the lead is $L^{*}(0,0, y)$. This is strictly higher than $F^{*}(0,0, y)$. However, in a $M P E$-compatible episode at $(0,0, y)$, such a value gap cannot be sustained. If a firm anticipates that its rival will first invest at $y_{00}^{L}$, then it is better-off preempting its rival at $y_{00}^{L}-d y$. This is true for any $y$ between $y_{00}^{p}$ and $y_{00}^{L}$. When the industry-wide shock $Y_{t}$ is equal to $y_{00}^{p}$, the value of both firms is the same, so each firm is indifferent between investing immediately and letting its rival invest while waiting to invest until $Y_{t}$ reaches $y_{01}^{*}$, at the stochastic time $\tau_{01}^{*}=\inf \left\{t \geq 0 \mid Y_{t} \geq y_{01}^{*}\right\}$. The following proposition is a transposition of Fudenberg and Tirole (1985, Proposition 2A) in a stochastic context.

Proposition 2 Under Assumptions 1 and 2 , if $Y_{0} \leq y_{00}^{p}$, there exists only one MPE-compatible episode outcome of the investment game at $(0,0, y)$ : one firm invests at $\tau_{00}^{p}$, while the other firm waits until $\tau_{01}^{*}$ to invest. Both times are stochastic and rents are equalized to the value of the second investor given by (3).

The simple MPE-compatible preemption episode in this case is characterized by intense competition. The first capacity unit is installed earlier than under protection from preemption since $y_{00}^{p}<y_{00}^{L}$, reflecting a partial dissipation of monopoly rents (Posner, 1975; Fudenberg and Tirole, 1987). A rise in uncertainty increases both $F^{*}$ and $L$ (see Figure 2) so that it may hasten investment (reduce $y_{00}^{p}$ ) in a $M P E$-compatible preemption episode. ${ }^{11}$

\subsubsection{Socially optimal investment timings}

It is more difficult to compare the $M P E$-compatible episode outcome with the social optimum at $(0,0, y)$. Specifically, let $k^{0}=\lceil D(0)\rceil$ be the minimum capital stock required to produce $D(0)$. The social planner's problem is to find an increasing sequence of stopping times that solves:

$$
\sup _{\tau_{1} \leq \cdots \leq \tau_{k} 0}\left\{\mathrm{E}_{y}\left[\sum_{k=1}^{k^{0}} \int_{\tau_{k}}^{\tau_{k+1}} e^{-r t} Y_{t} \int_{0}^{k} D^{-1}(q) d q\right]\right\}
$$

\footnotetext{
${ }^{11}$ This possibility that increased volatility could hasten investment was pointed out by Mason and Weeds (2005) when firms are limited to one investment each; we generalize this result to multiple investments.
} 
where by convention $\tau_{k^{0}+1}=\infty$. Standard computations imply that it is optimal for the social planner to invest in the first capacity unit when $Y_{t}$ reaches the investment trigger $y^{O}$ such that:

$$
y^{O} \int_{0}^{1} D^{-1}(q) d q=(r-\alpha) \frac{\beta}{\beta-1} I .
$$

From (7), we obtain $y^{O} \leq y_{00}^{L}$, with the equality satisfied if $\int_{0}^{1} D^{-1}(q) d q=\pi_{10}$. Since $y_{00}^{p}<y_{00}^{L}$ as well, there is no obvious way to compare $y^{O}$ and $y_{00}^{p}$ in general.

However, let $C S=\int_{0}^{1} D^{-1}(q) d q-\pi_{10}$ represent the generic net consumer surplus on the first capacity unit; it only depends on the slope of the demand function on $[0,1]$. In particular, $C S=0$ if the inverse demand curve is a step function, $D^{-1}(Q)=D^{-1}(\lceil Q\rceil)$, implying that $y^{O}=y_{00}^{L}>y_{00}^{p}$. Consequently, for any set of parameters defining $y_{00}^{p}$ and $y_{00}^{L}$, there exists a set of demand functions $D($.$) satisfying Assumption 1$ such that $C S$ is small enough for $y^{O}$ to be higher than $y_{00}^{p}$. This proves the following proposition.

Proposition 3 For any set of parameters determining $y_{00}^{p}$ and $y_{00}^{L}$, there exists a set of demand functions $D($. satisfying Assumption 1 such that the first industry investment occurs earlier in the MPE-compatible preemption episode than would be socially optimal at $(0,0, y)$.

Leahy (1993) discusses the timing of entry. In a model of industry capacity investments where investment units are of negligible size, he shows that the timing of investments is socially optimal under perfect competition, no matter what the demand function is. But in a duopoly, preemption accelerates entry. However, lumpy indivisible capacity units also imply that perfect competition is not socially optimal in general: unlike the social planner, competitive firms do not consider the consumer surplus when they compute profits, so that they underestimate the benefits of entry relative to the social planner. This factor postpones entry relative to the social optimum and may dominate the preemption effect when the net-of-price consumer surplus is big; it is small when the slope of the inverse demand is small and vanishes altogether when the inverse demand is a step function.

The result that the first industry investment may occur earlier under duopoly than is socially optimal does not depend on the market size assumption $k^{c}=1$. In particular it applies in the generalized treatment presented in Section 3.4 below. 


\subsection{Case 2: Symmetric positive capacities}

Let us now investigate the role of existing capacity, starting in this section with situations where firms have identical positive capacities, as illustrated by the subgame starting at node $(k, k)$ in Figure 1 . As in the previous subsection, we will assume that the firms hold a capacity lower than the unconstrained short-run Cournot output, which implies that both firms are initially capacity constrained and that a firm remains constrained if its opponent invests:

Assumption $30<x^{c}-k \leq 1$

Assumption 3 is compatible with an unconstrained monopoly output exceeding $k+1$, so that it does not rule out investments exceeding one unit, thereby allowing a firm to get ahead by more than one unit. It does imply that the end of the game is not too far in the sense that, by Proposition 1, the game is over once both firms have acquired at least one more unit. To simplify exposition without loss of generality, we take $k=1$. Then Assumption 3 implies that $\pi_{21}>\pi_{11}, \pi_{22}>\pi_{12}$, and $\pi_{\nu 2}=\pi_{22}=\pi_{2 \nu}, \forall \nu \geq 2$.

When considering a new investment, firms will now take into account the consequences on the profits they derive from their existing capacity. We will show that, as a result of the cannibalism effect, $M P E$ exhibiting tacit collusion at that node $(k, k)=(1,1)$ may exist besides the $M P E$ with preemption, provided that either late joint investment or no more investment dominates preemption over the whole relevant market development range.

\subsubsection{MPE-compatible preemption episode at $(k, k), k>0$}

A $M P E$-compatible preemption episode at $(k, k), k>0$ always exists along any MPE investment path. Let $k=1$. Indeed, assume that one of the firms has taken the lead by acquiring at least one new unit, bringing its total capacity to $\nu \geq 2$. For its rival, whatever the number of units held by the first investor, it is a dominant strategy by Assumption 3 to acquire one and only one unit at the market development threshold determined by the following stopping-time problem: for $y<y_{1 \nu}$,

$$
F^{*}(1, \nu, y)=\sup _{y_{1 \nu}}\left[\frac{\pi_{1 \nu}}{r-\alpha} y+\left(\frac{y}{y_{1 \nu}}\right)^{\beta}\left(\frac{\pi_{22}-\pi_{1 \nu}}{r-\alpha} y_{1 \nu}-I\right)\right]
$$


that is, at:

$$
y_{1 \nu}^{*}=\frac{r-\alpha}{\pi_{22}-\pi_{1 \nu}} I \frac{\beta}{\beta-1} .
$$

The situation is similar to the case with no initial capacity, except that the trigger value at which the second investor invests depends on the number $\nu$ of units held by the first investor. The higher $\nu$ is, the earlier the second investor will invest because its profits $\pi_{1 \nu}$, while he is waiting, are lower, the higher $\nu$ is.

The firm that invests first, whether it acquires one single unit or more units, understands the implications of its investment decision on the behavior of its competitor, so that $L(1,1, y)$ can be computed explicitly. For example, if the early investor acquires only one unit, its payoff at the current level of $y \leq y_{1 \nu}^{*}$ is, for $\nu=1$ :

$$
L(1,1, y)=\frac{\pi_{21}}{r-\alpha} y-I+\left(\frac{y}{y_{12}^{*}}\right)^{\beta}\left(\frac{\pi_{22}-\pi_{21}}{r-\alpha} y_{12}^{*}\right)
$$

As before, if the firm could choose the investment threshold in the absence of any threat of preemption, the maximum $L^{*}(1,1, y)$ with respect to $y$, for $\nu=1$, would be reached at: ${ }^{12}$

$$
y_{11}^{L}=\frac{r-\alpha}{\pi_{21}-\pi_{11}} I \frac{\beta}{\beta-1} .
$$

But under a preemption threat, it is not possible for the firm to achieve a value of $L$ exceeding $F^{*}$; it cannot wait until $Y_{t}$ reaches $y_{1 \nu}^{L}$; the best it can do is to invest at the trigger level $y_{1 \nu}^{p}$ at which $L(1,1, y)=F^{*}(1, \nu, y)$, so that rents are equalized. The following result parallels Proposition 2.

Proposition $4[M P E$-compatible preemption episode at $(k, k), k>0]$ Under Assumptions 1 and 3, the investment game has a MPE-compatible preemption episode at node $(k, k)$ such that, letting $k=1$, one firm invests when $Y_{t}$ reaches $y_{1 \nu}^{p}$, while the other firm invests when $Y_{t}$ reaches $y_{1 \nu}^{*}$.

In this MPE-compatible episode, the threat of preemption leads to rent equalization and thus to the complete dissipation of any first-mover advantage. However, with positive capacities, the preemption equilibrium episode may not be the unique $M P E$-compatible episode at positive capacity node $(k, k)$, as we shall now see.

\footnotetext{
${ }^{12}$ Again, the reader can adapt the candidate expressions for $L(1,1, y)$, with $y_{1 \nu}^{*}$ given by (10), for any new capacity purchase exceeding one unit $(\nu>2)$. The highest such candidate gives $L(1,1, y)$. It is certain to exist because, as shown in the proofs, the candidate for $L$ corresponding to $\nu=1$ exceeds $F^{*}(1,1, y)$ for some range of $y$ values lower than $y_{12}^{*}$.
} 


\subsubsection{MPE-compatible tacit collusion episode at $(k, k), k>0$}

As in Fudenberg and Tirole (1985), the fact that the firms hold strictly positive capacities gives rise to the possibility of a different type of $M P E$-compatible episode. In this alternative, the strategies involved consist in "coordinating" on a high joint investment threshold or in abstaining from investing forever, thereby postponing the rise in industry capacity and thus increasing firms' values. Note that short-run output decisions are still determined according to Cournot competition. Tacit collusion is achieved through investment timings, not through production decisions. This implies that firms can sustain a tacit collusion outcome through investing simultaneously, rather than at different times, and by doing so at a threshold $y_{12}^{s}$ exceeding $y_{12}^{*}$. Indeed if one of the firms were to invest at some $y<y_{12}^{*}$, the other firm's unique optimal continuation strategy would be to invest at $y_{12}^{*}$. This can be part of an MPE only if $y=y_{12}^{p}$ as shown in the analysis of the $M P E$-compatible preemption episode characterized above. Alternatively, if it were to invest at some $y \geq y_{12}^{*}$, then a dominant strategy for the other firm would be to follow suit and invest at the same time. Since simultaneous investments of one unit imply, by Assumption 3, that both firms then hold more capacity than the unconstrained Cournot output, they will not acquire more than one unit. Furthermore, the game is then over by Proposition 1.

Postponing investment or not investing restricts output. In that sense the tacit collusion equilibrium episode is reminiscent of the early-stopping equilibrium of Fudenberg and Tirole (1983) and of the tacitly collusive underinvestment equilibria of Nocke (2007) described earlier. ${ }^{13}$

Suppose that the firms could commit to invest simultaneously at some (random) future date or to abstain from investing forever. Given a current industry-wide shock $y$, the expected payoff that they could achieve in this way is, according to Lemma 1:

$$
S(1,1, y)=\frac{\pi_{11}}{r-\alpha} y+\left(\frac{y}{y_{11}^{s}}\right)^{\beta}\left(\frac{\pi_{22}-\pi_{11}}{r-\alpha} y_{11}^{s}-I\right)
$$

\footnotetext{
${ }^{13}$ However, Fudenberg and Tirole considered a dynamic game with downward sloping reaction functions in continuous investment levels. Such reaction functions imply that capacity is always scarce which may lead to a race to invest aimed at inducing the competitor to reduce its investment. We consider a dynamic game in lumpy investment. Once the capacity of the larger firm exceeds a certain level, the smaller firm is able fully to exploit its new capacity irrespective of any reaction by the larger firm; as a result the larger firm cannot indefinitely induce postponement of the smaller firm's investment by acquiring additional capacity. In that sense, even a preemption episode, where one firm invests early while the other firm waits, does not qualify as a race since both firms end up with the same value.
} 
If $\pi_{22}>\pi_{11}, S(1,1, y)$ has a maximum with respect to $y_{11}^{s}$, denoted $S^{*}(1,1, y)$, at $y_{11}^{s *}$ :

$$
y_{11}^{s *}=\frac{r-\alpha}{\pi_{22}-\pi_{11}} I \frac{\beta}{\beta-1}>y_{12}^{*}=\frac{r-\alpha}{\pi_{22}-\pi_{12}} I \frac{\beta}{\beta-1},
$$

with $\tau_{11}^{s *}=\inf \left\{t \geq 0 \mid Y_{t} \geq y_{11}^{s *}\right\}$ as the corresponding investment (stochastic) timing. If $\pi_{22} \leq \pi_{11}, S(1,1, y)$ attains a maximum of $\frac{\pi_{11}}{r-\alpha} y$ by letting $y_{11}^{s *}=\infty$ (tacit collusion by inaction), in which case $\tau_{11}^{s *}=\infty$. Clearly if $L(1,1, y)$ exceeds $S^{*}(1,1, y)$ at any $y \leq y_{11}^{s *}$, tacit collusion cannot occur in equilibrium since each firm then has an incentive to deviate and invest earlier. Hence,

Proposition 5 [MPE-compatible tacit collusion episode at $(k, k), k>0]$ Under Assumptions 1 and 3 and letting $k=1$, if $Y_{0} \leq y_{11}^{p}$,

1. A necessary and sufficient condition for the existence of a MPE-compatible tacit collusion episode at $(k, k)$ is $L(1,1, y) \leq S^{*}(1,1, y) \forall y<y_{12}^{*}$. If this inequality is strict for all such $y$, there exists a continuum of (MPE-compatible tacit collusion episodes, indexed by their joint investment triggers $y_{11}^{s}$ in the range $\left[\underline{y}^{s}, y_{11}^{s *}\right]$, where $y_{12}^{*} \leq \underline{y}^{s} \leq y_{11}^{s *}$.

2. Rents are equalized in each MPE-compatible tacit collusion episode and exceed the rents in the MPEcompatible preemption episode at the same node; the Pareto optimal MPE-compatible tacit collusion episode corresponds to the joint-profit maximizing investment rule under the constraint that firms invest simultaneously if they do. ${ }^{14}$ In this joint-profit maximizing MPE-compatible tacit collusion episode, each firm invests in one capacity unit with intensity:

$$
s_{1}^{f}(1,1, y)=s_{1}^{-f}(1,1, y)= \begin{cases}0 & \text { if } y \in\left[0, y_{11}^{s *}\right), \\ 1 & \text { if } y \in\left[y_{11}^{s *}, \infty\right) .\end{cases}
$$

3. If $\pi_{22}>\pi_{11}$, the Pareto optimal MPE-compatible tacit collusion episode has both firms investing when $Y_{t}$ reaches $y_{11}^{s *}$; otherwise, it is such that neither firm ever invests as $y_{11}^{s *}=\infty$.

Propositions 2 and 5 highlight the role of existing capacity in the exercise of market power. A firm that holds no capacity has no incentive to restrain output and thus a MPE-compatible tacit collusion episode cannot

\footnotetext{
${ }^{14}$ In the absence of that constraint, joint-profit maximization would involve sequential investments. Such an investment sequence cannot be sustained as an $M P E$-compatible outcome as it would generate a strictly higher expected payoff for the first investor and would, therefore, be subject to preemption.
} 
exist if one firm has zero capacity (Proposition 2). In the language of contestability, this says that the level of contestability is stronger when the contesting firm is not yet active. Moreover, the mere existence of an incentive to tacitly collude is not enough to guarantee that tacit collusion is sustainable in equilibrium: firms must also follow investment strategies such that a deviation from the tacit collusion outcome would trigger a reaction leading to a new equilibrium with a lower value for the deviating firm.

This "punishment" is made difficult because our assumption of a Cournot production equilibrium in any period implies that restraining output can only be achieved by postponing capacity investments in the industry. It follows, in particular, that the joint investment trigger in any $M P E$-compatible tacit collusion episode must be higher than both triggers in the MPE-compatible preemption episode characterized in Proposition 4. Moreover, a firm becomes more vulnerable to a deviation by its competitor once the trigger value for the first investment in the preemption equilibrium has been crossed: once $y>y_{11}^{p}$ and until $y$ reaches the threshold for the second investment, a deviation yields the defector a higher rent $L(\cdot)$ than the rent $F^{*}(\cdot)$ obtained by its competitor who would then invest optimally at $y_{12}^{*}$. Therefore, the rents $S^{*}(\cdot)$ under tacit collusion must be attractive enough (Proposition 5(2)) to beat such defection at any level of $y$ preceding $y_{12}^{*}$.

Proposition 5 provides a necessary and sufficient condition for the existence of MPE-compatible tacit collusion episodes at $(k, k)$. This condition implies restrictions on the components of $L(1,1, y)$ and $S^{*}(1,1, y)$ : first, the four profit values $\pi_{i j}$ determined by the non-stochastic component of demand $D(\cdot)$ under Cournot competition; second, the parameters underlying real option values, that is, the value of $\beta$ as determined by the discount rate $r$ as well as the drift $\alpha$ and the volatility $\sigma$ of the stochastic demand growth process.

Let $\widetilde{\Lambda}(\beta, I) \equiv\left\{\left(\pi_{11}, \pi_{12}, \pi_{22}, \pi_{21}\right) \mid S^{*}(1,1, y)-L(1,1, y) \geq 0 \forall y<y_{12}^{*}\right\}$ be the set of $\pi_{i j}$ quadruples for which $M P E$-compatible tacit collusion episodes exist given $\beta$ and $I$. The following proposition states that this set is non-empty, independent of $I$ (that is, $\widetilde{\Lambda}(\beta, I)=\Lambda(\beta)$ ), and larger in industries with higher volatility, faster demand growth and lower cost of capital (that is, $\Lambda\left(\beta^{\prime}\right) \subset \Lambda(\beta)$ iff $\beta<\beta^{\prime}$ ).

Proposition 6 [MPE-compatible tacit collusion episodes: existence] Under Assumptions 1 and 3,

1. There exists a set of market parameters guaranteeing the existence of MPE-compatible tacit collusion episodes at $(k, k), k>0$.

2. This set is independent of the investment cost I of a capacity unit. 
3. It is larger, the higher demand volatility is, the faster market growth is, and/or the smaller the discount rate or cost of capital is.

As we know from the real option literature, increased volatility raises the option value of an irreversible investment under no preemption threat: the firm increases its investment threshold to reduce the probability that the stochastic process reverts to undesirable levels after the firm has invested. The flexibility to do so increases the value of the firm and the more so, the higher the volatility. Such an effect is also present here.

There is another effect of volatility: an increase in volatility raises firm value more under tacit collusion than under preemption, thus favoring the emergence of the former. The reason comes from both timing and discounting. Tacit collusion involves higher investment thresholds (hence longer delays), while an increase in volatility amounts to a lower discount rate (recall that $\beta$ decreases with volatility $\sigma$ ) because it raises the probability that a given threshold value of $y$ will be reached in a given time span. Although instantaneous profits are always independent of $\beta$, the discounted value of the profit flows corresponding to each equilibrium does depend on $\beta$ : letting $k=1$,

the (state space) discount factors used in (12) and (11) are respectively $\left(\frac{y}{y_{11}^{s}}\right)^{\beta}$ and $\left(\frac{y}{y_{12}^{*}}\right)^{\beta}$ and, since $y_{11}^{s}>y_{12}^{*}$, the former increases more than the latter when $\beta$ decreases, that is, when volatility increases.

To put it differently, the benefits of restraining output through delaying investments occur in the distant future, that is, in a higher state of market development, while the benefits from deviating occur in the immediate future. Other things equal, higher volatility gives relatively more weight to the distant future, contrary to conventional wisdom whereby increased volatility, because it warrants a risk premium, amounts to an increase in the discount rate.

The intuition for such effects of the (time) discount rate and the market growth rate is similar: a lower discount rate favors future payoffs and a larger expected growth rate raises future prospects relative to immediate ones. Hence, both favor the existence of tacit collusion through a lower $\beta$.

\subsection{Case 3: Different capacities}

While we have shown that existing capacity is a necessary condition for tacit collusion between identical firms, capacity is also often said to play a role as a barrier to entry and thus can be used as a way to acquire and 
maintain a dominant position or a first-mover advantage. ${ }^{15}$

We consider now situations where firms differ in size. Referring to Figure 1, we now investigate investment subgames starting at nodes $\left(k, k^{\prime}\right), k \neq k^{\prime}$, and contrast them with those starting at node $(k, k)$ analyzed in the previous section. We showed that, with symmetric strictly positive capacities, there are two possible types of investment episodes: preemption and tacit collusion. The former always exists, is highly competitive and involves rent equalization. The latter exists under some conditions, provides higher rents to both firms, and also involves rent equalization. We will show that some of these characteristics are modified under asymmetric capacities: initial capacity asymmetry prevents rent equalization and makes collusion more difficult in the sense that the maximization of joint profits is no more compatible with a MPE.

Assumption $40<x^{c}-k \leq 2$.

Again, this assumption indicates that we are close to the end of the investment game. Without loss of generality, we let one firm hold $k=1$ capacity units and the other $k^{\prime}=k+1=2$ units. The unconstrained Cournot output is then either $1<x^{c} \leq 2$ or $2<x^{c} \leq 3$, with $\pi_{31}>\pi_{21}, \pi_{2 \nu}>\pi_{1 \nu}, \forall \nu$.

Consider first the case where $1<x^{c} \leq 2$. The larger firm holding two units may be capacity constrained when the smaller firm holds only one unit, but it will become unconstrained if the smaller firm invests in a second capacity unit. Thus, by Proposition 1, the investment game cannot be over at node $(1,2)$. If the smaller firm invests, both firms then hold enough capacity to produce $x^{c}$ and the game is over by Proposition 1 . Moreover, the smaller firm benefits more from acquiring one new unit than the bigger firm does and the net benefit from investing is positive at high enough levels of $Y_{t}$. Therefore, the smaller firm is the sole investor in equilibrium and the game ends when both firms hold two units of capacity.

Consider now the case where $2<x^{c} \leq 3$. Both firms hold a lower capacity than the unconstrained shortrun Cournot output so that both are initially constrained and each firm remains constrained if its opponent invests. By Proposition 1 this may be the end of the game, although not necessarily so; this possibility will be considered further below. Two alternative candidate preemption equilibrium episodes may be considered: one, where the bigger firm invests first and the smaller firm acts accordingly; another, where the roles are reversed. The corresponding values of the bigger and the smaller firm, acting as first or second investor are respectively

\footnotetext{
${ }^{15}$ See for instance Spence (1979), Dixit (1980), Fudenberg and Tirole (1983).
} 
$L(2,1, y)$ and $F^{*}(2,1, y)$ for the bigger firm, and $L(1,2, y)$ and $F^{*}(1,2, y)$ for the smaller firm. ${ }^{16}$

When the smaller firm invests first, node $(2,2)$ is reached and both firms remain capacity constrained, which is the situation we analyze in Subsection 3.2: both firms then hold two units of capacity and assumption 3 holds with $k=2$, so that Propositions 4, 5, and 6 apply. The continuation of the game is then known so that $L(1,2, y)$ and $F^{*}(2,1, y)$ can be computed. If the bigger firm invests first, then it is a dominant strategy for the smaller firm to invest at some finite future level of $Y_{t}$, since $\pi_{13}<\pi_{23}<\pi_{33}$ as the larger firm must accommodate (Cournot equilibrium). It is then straightforward to obtain $L(2,1, y)$ and $F^{*}(1,2, y)$.

We will show that, in any MPE-compatible preemption episode starting at nodes $\left(k, k^{\prime}\right), k \neq k^{\prime}$, the first firm to undertake an additional unit investment is the smaller firm. In order to prove that result, we need the following lemma.

Lemma 2 If $L(2,1, y)>F^{*}(2,1, y)$ for some $y<y_{13}^{*}$, then there is exactly one value $y_{12}^{p} \in\left(0, y_{13}^{*}\right)$ such that $L\left(2,1, y_{12}^{p}\right)=F^{*}\left(2,1, y_{12}^{p}\right)$ and $L(2,1, y)<F^{*}(2,1, y)$ for $y<y_{12}^{p}$.

The lemma indicates that, by investing at $y=y_{12}^{p}$, the smaller firm leaves the bigger firm indifferent between investing immediately or waiting. Furthermore, we show in the proof of the next proposition that, at $y=y_{12}^{p}$, the smaller firm strictly prefers to invest. Also, at any other relevant level of $y$, the gain for the bigger firm from investing first is smaller than the gain for the smaller firm to do so. These results imply that the sole preemption equilibrium is one where the smaller firm catches up. Trivially, if the bigger firm finds it unprofitable to invest, then the smaller firm can invest at its stand-alone date $y_{12}^{*}$ without worrying about preemption.

Proposition $7\left[M P E\right.$-compatible preemption episode at $\left.\left(k, k^{\prime}\right), k>0, k^{\prime}>k\right]$ Under Assumptions 1 and 4 , letting $k=1$ and $k^{\prime}=2$,

1. There exists a MPE-compatible preemption episode at $\left(k, k^{\prime}\right)$; in this episode, the smaller firm invests first, when $Y_{t}$ first reaches $\min \left\{y_{12}^{p}, y_{12}^{*}\right\}$.

2. In this MPE-compatible preemption episode, the smaller firm enjoys a strictly positive rent from investing first as $L\left(1,2, y_{12}^{p}\right)-F^{*}\left(1,2, y_{12}^{p}\right)>0$, while the bigger firm is either indifferent between investing

\footnotetext{
${ }^{16}$ Explicit expressions are given in the proof of Lemma 2. As in previous cases, it is tedious but conceptually easy to check whether the first-mover acquires one or more new capacity units before its rival invests. To simplify the analysis, we treat the case where the first-mover acquires only one extra unit.
} 
immediately and waiting, or prefers waiting as $L\left(2,1, y_{12}^{p}\right)-F^{*}\left(2,1, y_{12}^{p}\right) \leq 0$.

3. Once node (2,2) is reached, Proposition 4 applies, mutatis mutandis.

Unlike the situation with equal capacities, there is not ambiguity as to which firm invests first. The reason is not because the laggard (smaller firm) is in a better position to avoid immediate cannibalism: the drop in price is the same, whichever firm invests. Thus, the source of the first-mover advantage must be found in future decisions rather than current effects. If the bigger firm were investing first, the other firm could plan its own investment at its stand-alone date. Having less to lose from the cannibalism effect, it would invest earlier in the future than a bigger firm would. This reduces, for its bigger competitor, the advantage of taking the lead.

While the same drop in price occurs whichever firm invests first, the laggard (smaller firm) experiences a lower drop in revenues from its existing capacity, simply because it holds fewer units. This, combined with the higher advantage from taking the lead, explains why the smaller firm enjoys a larger gain in value in that preemption episode.

The MPE-compatible episode described in Proposition 7 always exists and it is unique in the class of $M P E$ compatible episodes involving investment by both firms at different dates or investment by one firm only, when capacities differ. As with equal capacities, there may exist another class of $M P E$-compatible episodes, tacit collusion ones involving simultaneous investment or inaction by both firms. The next proposition shows that, as with equal capacities, higher volatility, faster growth and lower discount rate make $M P E$-compatible tacit collusion episodes more likely.

Proposition $8\left[M P E\right.$-compatible tacit collusion episodes at $\left.\left(k, k^{\prime}\right), k>0, k^{\prime}>k\right]$ Under Assumptions 1 and 4 , letting $k=1$ and $k^{\prime}=2$,

1. If $\pi_{32}-\pi_{22}=0$ : no MPE-compatible tacit collusion episode exists.

2. If $\pi_{32}-\pi_{22}>0$ : the set of market parameters ensuring the existence of MPE-compatible tacit collusion episodes is larger, the larger demand volatility is, the faster market growth is, and/or the smaller the discount rate or cost of capital is.

3. Joint-profits maximization cannot be achieved in a MPE-compatible tacit collusion episode. 
As discussed in the case of equal capacities, tacit collusion involves postponing capacity investments in order to restrain output. Benefits from tacit collusion arise in a more distant future than benefits from taking the lead. Consequently, the existence of a tacit collusion equilibrium rests on conditions under which the future weighs relatively more, either because of significant market growth, or because of high volatility, or because of a low discount rate, as previously. However, tacit collusion is less attractive when firms hold different capacities since joint-profit maximization is not compatible with equilibrium: being different, firms prefer different thresholds for simultaneous investment. The threshold $y_{12}^{s *}$ that maximizes the payoff $S(1,2, y)$ of the smaller firm in case of simultaneous investment is lower than the threshold $y_{21}^{s *}$ for the bigger firm. The joint-profit maximizing threshold is somewhere in between. Since the payoff of the smaller firm decreases in $y$ beyond its maximum, the smaller firm would deviate (invest earlier) from a strategy of joint investment at the joint-profit maximizing threshold.

\subsection{Generalization}

We have considered explicitly three types of investment games in this section: games with zero initial capacity $(0,0)$, equal but strictly positive initial capacities $(k, k)$, and different but strictly positive initial capacities $\left(k, k^{\prime}\right)$. It was assumed that the initial state of market development $y$ was "low", so that any further investments occurred at thresholds higher than $y$. In each case, the number of possible remaining investments was limited by a further assumption on generic demand $D($.$) : Assumption 2,0<x^{c} \leq 1$, for the $(0,0)$ case; Assumption $3,0<x^{c} \leq 2$, for the $(k, k)$ case with $k=1$; and Assumption $4,0<x^{c} \leq 3$ for the $(k, k+1)$ case with $k=1$. Let us now consider the general case by assuming that generic demand is such that: $2<x^{c} \leq 3$. We now have a single game that can be solved by adapting the above results slightly or using them directly, for any initial state of the game (capacity pair and market development).

This is illustrated in Figure 3 giving possible capacity combinations and investment sequences when generic demand is such that $2<x^{c} \leq 3$. Since the game is symmetric, we represent only combinations where Firm 1 is at least as big as Firm 2. There is an infinity of potential initial states of the game; we are interested in industry development, that is, in the characterization of investment sequences occurring in $M P E$ as market develops from an initial state characterized by capacities $(0,0)$ and a low level of market development. ${ }^{17}$ The states considered in Figure 3 are limited to those that can be reached from an initial $(0,0)$ capacity combination. We also ignore capacities in excess of the monopoly capacity as they would not be reached in any $M P E$ of a game with low initial

\footnotetext{
${ }^{17}$ This restriction in initial states is made only for the sake of saving space while focusing on economically interesting situations.
} 
capacities. $^{18}$

Many characteristics of the game or of its (possibly several) MPE follow directly from the results established earlier and are incorporated into Figure 1. Nodes that are necessarily endgame nodes, according to Proposition $1(A)$ are represented with square brackets in the figure: $[4,3]$ and $[3,3]$. The other possible endgame nodes are defined by Proposition $1(B)$ and denoted with curly brackets: $\{2,1\},\{1,1\}$ and $\{2,2\}$; they correspond to tacit collusion episodes, in the sense of Propositions 5, 6, and 8.

Investments occurring in an equilibrium sequence are indicated by single arrows in the cases of individual moves (preemption episode or stand-alone investment) or double arrows in the cases of simultaneous investments (tacit collusion episode). A question mark next to an arrow indicates that a $M P E$ including such an episode may or may not exist in the sense of Propositions 6 and 8. We call the game illustrated in Figure 3 the complete game.

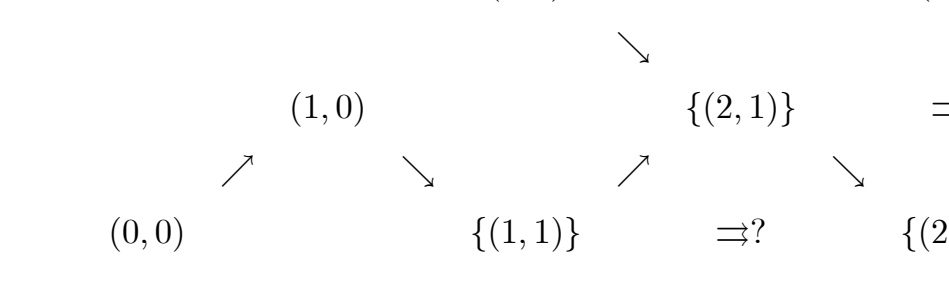

$\{(.,)$.$\} : potential endgame;$

$[(.,)$.$] : endgame (if reached);$
$(4,1)$

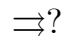

$\{(2,2)\}$
$(4,2)$

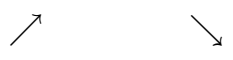

$\rightrightarrows ? \quad[(3,3)]$

$\rightrightarrows$ ?: potential tacit-collusion MPE episode; $\nearrow$ : stand-alone or preemption MPE episode.

Figure 3: Complete industry development game when $x^{c}=3$

A subset of Figure 3 consisting of any capacity pair $(i, j)$ and all pairs $\left(i^{\prime}, j^{\prime}\right)$ such that $i^{\prime} \geq i$ and $j^{\prime} \geq j$ may be viewed as a particular stochastic game. With a slight abuse of language, we will call such a game the subgame starting at $(i, j)$. Although the particular combination $(i, j)$ is not necessarily reached in a $M P E$ of the complete game when the initial capacity pair is $(0,0)$, the solution of the subgame starting at $(i, j)$ describes the solution of the complete game for some possible initial states of that game. For example, although the capacity pair $(4,0)$ is not reached in any $M P E$ of the complete game when the initial capacity level is $(0,0)$, the subgame starting

\footnotetext{
${ }^{18}$ For a linear inverse demand curve $P=\left(1-\frac{X_{1}+X_{2}}{8}\right) Y_{t}, x^{c}=k^{c}=3$ and the maximum monopoly capacity is $k^{m}=4$.
} 
at $(4,0)$ has an obvious unique $M P E$ where the bigger firm never invests since it already holds the monopoly capacity, and the smaller firm invests sequentially when $Y_{t}$ reaches its stand-alone thresholds until it holds the Cournot capacity $x^{c}=3$. The relevant portions of that sequence also describe the $M P E$-compatible subgames starting at $(4,2)$ and $(4,1)$.

The subgame starting at node $(2,2)$ satisfies Assumption 3 for $k=2$. Consequently, by Proposition 4 , there is a $M P E$-compatible preemption episode starting in that state; this episode can only lead to an end at [3,3]. As described in Propositions 5 and 6 , the subgame starting at $(2,2)$ may also have a MPE-compatible tacit collusion episode, denoted by the double arrow with a question mark. In that case, the end is either at $(2,2)$ if tacit collusion involves never investing or at $(3,3)$ (Proposition 5.3$)$ : firm values at $(2,2)$ are equalized, but higher (by Proposition 5.2$)$ than in the MPE-compatible preemption episode at $(2,2)$.

Trivially, subgames starting at $(3,0),(3,1)$, or $(3,2)$ can only end at $[3,3]$; the bigger firm is either passive, in which instance the smaller firm invests at its stand-alone thresholds, or is preempted by the smaller firm in any equilibrium sequence leading to $(3,3) .{ }^{19}$

The subgame starting at node $(2,1)$ is studied in Propositions 7 and 8 . From $(2,1)$ the preemption equilibrium path leads to $(2,2)$ for a possible end of game at $(2,2)$ or continuation to $(3,3)$, whether directly in a tacit collusion episode or via $(3,2)$ in a preemption episode. There may also exist a tacit collusion episode from $(2,1)$ to $(3,2)$.

The subgame starting at $(1,1)$ has not been studied for $x^{c} \leq 3$ but only for $x^{c} \leq 2$. However, now that its two possible continuations, via $(2,1)$ or via $(2,2)$, are known, Propositions 4,5 , and 6 may be adapted accordingly. More precisely, suppose that the equilibrium investment sequence is $(1,1) \rightarrow(2,1)$. When applying Lemma 1 to evaluate $L(1,1, y)$, one must substitute for the continuation value $c(2,1, y)$. If the next equilibrium segment is the preemption segment $(2,1) \rightarrow(2,2)$, this is $F^{*}(2,1, y)$ as given in the proof of Lemma 2 ; similarly, the expression for $F^{*}(1, \nu, y), \nu=1$, given by (9) for $x^{c} \leq 2$ must be replaced by the expression applying when $x^{c} \leq 3$, as provided in the proof of Lemma 2. Alternatively, if the next equilibrium segment is the tacit collusion segment $(2,1) \rightarrow(3,2)$, then $c(2,1, y)$ is equal to $S(2,1, y)$ given in the proof of Proposition 8 . The qualitative

\footnotetext{
${ }^{19}$ For example, consider the possible alternatives from $(3,0)$ : either the bigger firm invests first, leading to $(4,0)$ and a continuation with the small firm investing at its stand-alone thresholds until $[4,3]$ is reached; or the small firm invests first, leading to $(3,1)$, $(3,2)$, and $(3,3)$, or to $(3,1),(4,1),(4,2)$ and $(4,3)$. Two conditions are necessary for the first alternative to be part of a $M P E$ : first, the monopoly tenure of the big firm on its fourth unit must be sufficiently long to earn back the investment cost $I$ on the unit; second, the small firm must not invest before the bigger one. Adapting the proof of Proposition 7 where it is shown that the smaller firm invests first in the MPE-compatible preemption episode starting in that state, it can be shown that the first condition is violated if the second one is satisfied.
} 
results are unchanged: the subgame starting at $(1,1)$ always admits a $M P E$-compatible preemption episode via $(2,1)$ and $(2,2)$; a MPE-compatible collusion episode with simultaneous investments leading directly to $(2,2)$ may exist depending on conditions described in Proposition 6. In both cases, the continuation payoffs are known and the game ends at $(2,2)$ or $(3,3)$. If a $M P E$-compatible collusion episode exists for the subgame starting at $(2,1)$, Proposition 8 indicates that it does not exhibit rent equalization. Then, by the standard preemption argument used repeatedly in this paper, the corresponding $M P E$-compatible preemption episode at node $(1,1)$ takes this asymmetry into account: the first investor invests at such a threshold that firm values at node $(1,1)$ are equalized: $L(1,1, y)=F^{*}(1,1, y)$.

Comparing the subgames starting at $(1,1)$ and at $(2,2)$, we note that a $M P E$-compatible preemption episode always exists and MPE-compatible collusion episodes may exist. However, the subgame starting at $(1,1)$ may also involve a tacit collusion episode from $(2,1)$ to $(3,2)$, unlike the subgame starting at $(2,2)$ where tacit collusion at $(3,2)$ is not possible.

This raises the issue of multiple equilibria. We have shown, however, that firm values are higher under tacit collusion than under preemption in the subgame starting at $(2,2)$. Although we do not provide a formal proof, this is also likely to be the case in the subgame starting at node $(1,1)$ and equilibrium episodes can probably be Pareto ranked. In any case, if tacit collusion from node $(2,1)$ is a possible $M P E$-compatible episode, it leads to $(3,2)$. By Proposition 1, this cannot be the end of the game as it is a dominant strategy for the smaller firm to acquire one further unit and for the bigger one to abstain, so node $(3,3)$ is reached. By Proposition 1 , this is the end of the subgame, with both firms holding equal capacities.

Turning to the subgames starting at $(1,0)$ and $(2,0)$, it can be shown, by adapting the proof of Lemma 2 , that the small firm invests first from $(1,0)$ or from $(2,0)$. Finally, considering the initial node $(0,0)$, it is now trivial to adapt Proposition 2 replacing the continuation values corresponding to the initial Assumption 2 with the equilibrium values for the subgame starting at $(1,1)$ under the new assumption $x^{c} \leq 3$. A unique MPE-compatible preemption episode prescribing investment from $(0,0)$ to $(1,1)$ via $(1,0)$ exists for each possible continuation payoff at $(1,1)$. As discussed above, several continuation payoff may exist from that node on, all leading to equal size firms at the end of the game, as indicated in Figure 3 and further discussed in the conclusion below.

Thus, under assumption $x^{c} \leq 3$, the complete game can be solved entirely following the procedure just 
described. Further generalization to higher industry sizes would not affect the qualitative properties of the model, which we summarize in the concluding section after we discuss the restrictions if any imposed on the generality of our results by our choice of Cournot competition on the product market.

\subsection{Prices versus quantities as short-run strategic variables}

We have shown in this paper that MPE-compatible investment paths may include both episodes of harsh preemption competition and episodes of softer tacit collusion between the firms. Moreover, the investment game eventually leads to firms of equal size. Would these results survive if firms competed day to day in capacityconstrained prices rather than in capacity-constrained quantities as assumed in this paper?

In Boyer et al. (2004), we developed a duopoly model of competition aimed at better understanding the extent to which cooperation rents are dissipated through competition in investments over time. We considered the emergence of preemption with multiple investments and instantaneous price competition on a market of finite size driven by stochastic taste shocks, somewhat in the spirit of the present paper. We showed that different patterns of equilibria may arise, depending on the importance of the real option effect. If the average growth rate of the market is large enough relative to the risk-free rate or cost of capital, or if demand volatility is high enough, there is a Markov perfect equilibrium outcome where firms simultaneously invest in one unit of capacity at the random time that maximizes industry profits (soft competition). Because the duopoly exactly duplicates the monopoly outcome, no rent dissipation occurs. That equilibrium is furthermore unique unlike the cooperative equilibria found by Fudenberg and Tirole (1985) of which it is reminiscent. It is also striking that despite significant indivisibilities in investments, it is not worthwhile for the incumbent to erect temporary barriers to entry by accumulating capacity. However, if the cost of capital is high relative to the average growth rate of the market and if the volatility of demand is low enough, then firms will simultaneously invest in one unit of capacity at the first date at which it would become worthwhile to preempt one's rival with two units of capacity (harsher competition). This occurs earlier than the optimal monopolistic investment date, implying that some monopolistic rents are dissipated in equilibrium, but does not lead to complete rent dissipation. We concluded that instantaneous price competition by and large leads to positive rents in that duopoly investment game; furthermore, the investment game leads to firms of equal size.

Besanko and Doraszelski (2004) aimed at better understanding the forces that shape the size distribution of 
firms in an industry. They showed that industry dynamics critically depend on the mode of product market competition and on the degree to which investment is irreversible. While our concept of preemption is based on the timing of investments, their's is based on the level of investments: during a preemption race, firms rush to build capacity in order to eventually take a leadership advantage. Under quantity competition, each firm would accumulate enough capacity to supply the Cournot quantities, leading to an industry structure of equal-sized firms irrespective of whether investment is irreversible or not. By contrast, under price competition, there are forces that propel the industry toward asymmetric structures. This is more pronounced when investment is reversible as disengaging from the preemption race is less costly. However, if investment is significantly irreversible, these forces towards asymmetry are rather weak and firms are likely to remain of similar size except for asymmetries that may arise accidentally. An interesting aspect of the paper is indeed the analysis of the role reversibility plays in determining the intensity of competition and the size distribution of firms.

Besanko al. (2010) revisited the determinants of capacity building in preemption races and in coordinated capacity withdrawals. They considered in particular the role of reversibility in shaping the long-run structure of an industry. They studied the dynamics of an oligopolistic industry with differentiated products, lumpy capacity, and lumpy investment or disinvestment under incomplete information regarding competitors' costs. They modeled price competition with soft budget constraints and with rapidly increasing costs at production levels in the neighborhood of capacity. To avoid specifying a rationing rule, a thorny issue of capacity constrained price competition models, they imposed the requirement that a firm is obliged to satisfy all of its demand. ${ }^{20}$ They showed in a series of examples that low product differentiation and low investment sunkness tend to promote preemption races early and capacity coordination lately. However, if firms lack the option to disinvest, they have no reason to enter a preemption race in the first place because they anticipate that the industry will be permanently locked into a state of excess capacity and low profitability after the race. Hence, under costly disinvestment, firms tend to avoid harsh preemption, which prevents any one of them from taking a leadership position and leads to relatively similar firm sizes.

\footnotetext{
${ }^{20}$ The more standard feature is to allow firms to satisfy demand up to the produced or marketed quantity, possibly butnot necessarily equal to capacity as a hard constraint. Boyer and Moreaux $(1988,1989)$ claim that, even in cases without capacity constraints, there is no sound reason to impose on firms that they satisfy all of their respective demand. They proposed models where firms compete in price-quantity pairs $(p, q)$ rather than in prices $p$ or quantities $q$.
} 


\section{Conclusion}

We characterized the development of a stochastically growing market under duopoly where firms build capacity through multiple irreversible lumpy investments in production units without any exogenously given order of moves or any commitment regarding future investments. Firms make optimal strategic use of their flexibility to adapt to the stochastic evolution of the market. The model shares important features of some "real life" investment games and generates stylized characteristics of developing industries, including the occurrence of joint investments (waves) and the eventual reach of maturity.

We found that the early phase of development is characterized by intense competition despite the fact that only one firm may be active at that stage. Competition intensity may cause the first industry investment to occur earlier than would be socially optimal. Indeed equilibrium requires equal payoffs or values for both firms despite the fact that they invest at different market development stages. This strong equilibrium condition leads one firm to enter earlier than would be desirable in order to dissipate the monopoly rent it would have enjoyed over its competitor by being alone in the first phase of the game. This is the sole equilibrium pattern at the beginning of the investment game. The empirical implication of this result is that the first entrant enters at a very early stage of the market development process and thus faces riskier returns and a higher probability of bankruptcy than under perfect competition. Higher uncertainty tends to exacerbate that effect in the sense that higher uncertainty may cause the first industry investment to occur earlier.

The smaller firm eventually catches up and the larger firm cannot indefinitely keep its opponent at bay, even if it holds enough capacity to serve the whole market. Indeed, being bigger makes the threat of early subsequent investment less credible. Consequently, in the initial MPE-compatible preemption episode of a game starting with firms of different sizes, it is the smaller firm that moves and invests first.

MPE-compatible tacit collusion episodes may occur only at states of the game where both firms hold positive capacity; they take the form of postponed simultaneous investments by both firms. Such equilibria are more likely to exist in highly volatile and/or faster growing markets, and low cost of capital situations. Suppose that the volatility level is such that no $M P E$-compatible tacit collusion episode exists at some state $\left(k, k^{\prime}, y\right)$. It is known already that a rise in volatility delays investment; we found that this effect may be compounded if the rise in volatility further allows a $M P E$-compatible tacit collusion episode to come to existence. The firms may 
then tacitly coordinate and select the higher payoff equilibrium by further delaying their next investments till a common trigger is reached. This effect of volatility appeared in Boyer et al. (2001).

The analysis of multiple investment opportunities has confirmed results that existed with a single opportunity. It has also brought a new perspective on competition at different stages of the development of an industry. Early stages are characterized by intense competition; tacit collusion is only possible at subsequent stages, when firms hold positive capacity; tacit collusion is more likely to exist in industry characterized by high growth, high volatility and/or low cost of capital; market power can also be exercised at later stages, whether as tacit collusion implemented by not investing, or as final equilibrium episodes where the smaller firm catches up while investing at its stand alone market development triggers.

At any industry development stage, however, if tacit collusion is $M P E$-compatible, it is more profitable between firms of equal size than between unequal firms. When firms are of equal size, tacit collusion is compatible with joint-profit maximization, but when firms differ in size, the simultaneous investment threshold that maximizes joint profits is beyond the level that maximizes the expected value of the smaller firm. In that sense, tacit collusion is unable to generate the totality of potential gains from collusion when firms are of unequal sizes. If they can select an equilibrium investment sequence that maintains size equality, it is in the interest of the firms to do so. As extension of the analysis, this also suggests that explicit coordination, such as alliances, acquisitions and mergers, may be more attractive, relative to tacit collusion, the more unequal the firm sizes are.

Our results imply that traditional measures of competition intensity may be deceiving: competition is more intense when one single firm is investing, as preemption is then the sole equilibrium episode, while tacit collusion is more likely when both firms are active, are of equal size, and the market develops quickly, with much volatility, under a low cost of capital. Indeed faster and more volatile market growth puts remote occurrences within closer reach. Tacit collusion precisely relies on exposition to such remote future benefits. 


\section{Appendix: Proofs}

Proof of Lemma 1. Let $Y_{t}=y$. The value of a firm at date $t$ is the expected present value of its profits over the periods between investments by either firm, minus the present value cost of the investments made by the firm. In the case of a firm of capacity $i$ that invests immediately, at $t$, while its opponent holds $j$ units and does not make any investment at $t$,

$$
\begin{aligned}
L(i, j, y) & =E^{y}\left\{\int_{t}^{\tau_{k j}} e^{-r s} \pi_{k j} Y_{s} d s+e^{-r \tau_{k j}}\left[c\left(k, j, Y_{\tau_{k j}}\right)\right]\right\}-I \\
& =E^{y}\left\{\int_{t}^{\infty} e^{-r s} \pi_{k j} Y_{s} d s-\int_{\tau_{k j}}^{\infty} e^{-r s} \pi_{k j} Y_{s} d s+e^{-r \tau_{k j}}\left[c\left(k, j, Y_{\tau_{k j}}\right)\right]\right\}-I
\end{aligned}
$$

where $\tau_{k j}$ is the random time, possibly infinite, at which some further investment occurs. The profit flow $\pi_{k j} Y_{s}$ replaces $\pi_{i j} Y_{s}$ at $t$. If it is altered by some new investment by either firm later on, at $\tau_{k j}$, the continuation function $c\left(k, j, Y_{\tau_{k j}}\right)$ accounts for the new state.

The time homogeneity of $\left(Y_{t}\right)_{t \geq 0}$ and the strong Markov property for diffusions imply that, for all $y \geq 0$,

$$
L(i, j, y)=\frac{\pi_{k j}}{r-\alpha} y-I+E^{y}\left\{e^{-r \tau_{k j}}\left[c\left(k, j, Y_{\tau_{k j}}\right)-\frac{\pi_{k j}}{r-\alpha} Y_{\tau_{k j}}\right]\right\}
$$

We are interested in stopping regions of the form $\left[y_{k j}, \infty\right)$. For any $y_{k j}>0$, let $\tau\left(y_{k j}\right)=\inf \left\{t>0 \mid Y_{t} \geq y_{k j}\right\}$, so that $Y_{\tau\left(y_{k j}\right)}=y_{k j} P-a . s . ;$ then $L(i, j, y)$ may be rewritten as:

$$
L(i, j, y)=\frac{\pi_{k j}}{r-\alpha} y-I+E^{y}\left\{e^{-r \tau\left(y_{k j}\right)}\right\}\left[c\left(k, j, y_{k j}\right)-\frac{\pi_{k j}}{r-\alpha} y_{k j}\right]
$$

Following Harrison (1985, chapter 3), the Laplace transform $E^{y}\left\{e^{-r \tau\left(y_{k j}\right)}\right\}$ is $\left(\frac{y}{y_{k j}}\right)^{\beta}$ for any $y \in\left[0, y_{k j}\right)$. Substituting into (14) yields the formula for $L(i, j, y)$ given in the Proposition. The other expressions are obtained in a similar way.

Proof of Proposition 1. A strictly positive capacity is necessary. Suppose one firm has zero capacity. Then its profit is zero. If it buys one unit, the lowest instantaneous profit it can make at any time after making that investment is $Y_{t} \pi_{1 k}$, where $k$ is the capacity at which its opponent is unconstrained in the short run in response to an output of one: this corresponds to the worst-case scenario where its opponent holds the capacity which leaves the firm the lowest instantaneous profit and the firm does not acquire any further units even if it is profitable for it to do so. The maximized expected discounted present value from buying one capacity unit at some future time $\tau$ is, in that worst-case scenario, $V(0, k, y)=\sup _{\tau} E^{y}\left\{\int_{\tau}^{\infty} e^{-r t} Y_{t} \pi_{1 k} d t-e^{-r \tau} I\right\}$. Using the approach of Lemma 1 to evaluate $V$ leads to $V(0, k, y)=\sup _{y_{0 k}}\left(\frac{y}{y_{0 k}}\right)^{\beta}\left(\frac{\pi_{1 k}}{r-\alpha} y_{0 k}-I\right)$. The value of $y_{0 k}$ that solves the maximization is $y_{0 k}^{*}=\frac{I(r-\alpha)}{\pi_{1 k}} \frac{\beta}{\beta-1}$ so that $V(0, k, y)>0$. Thus, the strategy of never buying in the future is strictly dominated for the firm whose capacity is zero. In consequence, both firms will eventually hold strictly positive capacity.

Either $A$ or $B$ is necessary. Assume that neither $A$ nor $B$ holds, that is: let $l$ and $k$ be the respective capacities; let $l$ be such that the corresponding firm is capacity constrained and let $k$ be such that the firm that holds $k$ units is not constrained if the other firm has a capacity of $l+1$ or more units. If the first firm increases its capacity to $l+1=n$, its current instantaneous profit increases to $Y_{t} \pi_{n k}>Y_{t} \pi_{l k}$ and stays at that level forever since the opponent, not being capacity constrained, has no alternative but to accommodate by reducing output. 
The maximized gain in expected discounted present value from bringing capacity to $n$ at some future time $\tau$ is $V(l, k, y)=\sup _{y_{l k}}\left(\frac{y}{y_{l k}}\right)^{\beta}\left(\frac{\pi_{n k}-\pi_{l k}}{r-\alpha} y_{l k}-I\right)$. This is positive, implying that a strategy of never investing in a situation where one firm is constrained, while the other is unconstrained or would become unconstrained after a unit investment by its opponent, is strictly dominated.

Condition $A$ is sufficient. If neither capacity constraint is binding, no firm can increase profit by further investing so that the game is necessarily over.

Proof of Proposition 2. As shown in the main text, if a firm invests the first time $Y_{t}$ reaches $y$ from below while the other firm waits, its payoff is $L(0,0, y)$ as given by $(5)$ and the payoff of its opponent is $F^{*}(0,0, y)$ given by $(3)$. If both firms invest simultaneously at $Y_{t}=y$, taking $y_{00}^{s}=y$ in Lemma 1 , their payoff is, $\widetilde{S}(0,0, y)=\frac{\pi_{11}}{r-\alpha} y-I$. Let: ${ }^{21}$

$$
\begin{aligned}
& s_{1}^{f}(0,0, y)=s_{1}^{-f}(0,0, y)=\left\{\begin{array}{l}
0, \text { if } y \in\left[0, y_{00}^{p}\right) \\
\frac{L(0,0, y)-F^{*}(0,0, y)}{L(0,0, y)-\widetilde{S}(0,0, y)}, \text { if } y \in\left[y_{00}^{p}, y_{01}^{*}\right) \\
1, \text { if } y \in\left[y_{01}^{*}, \infty\right)
\end{array}\right. \\
& s_{1}^{f}(0, \nu, y)=s_{1}^{-f}(0, \nu, y)=\left\{\begin{array}{l}
0, \text { if } y \in\left[0, y_{01}^{*}\right), \nu \geq 1 \\
1, \text { if } y \in\left[y_{01}^{*}, \infty\right), \nu \geq 1
\end{array}\right. \\
& s_{1}^{f}\left(\nu, \nu^{\prime}, y\right)=s_{1}^{-f}\left(\nu, \nu^{\prime}, y\right)=0 \forall y ; \nu, \nu^{\prime} \geq 1,
\end{aligned}
$$

where $s_{1}^{f}(i, j, y)$ is a probability distribution satisfying the detailed definition given in Boyer et al. (2004, Appendix A). It can be interpreted as the intensity with which firm $f$ invests in one unit of capacity in state $(i, j, y), i . e$. when it holds $i$ capacity units, its opponent holds $j$ units, and $Y_{t}=y$. We have shown already that, on $\left[0, y_{00}^{p}\right)$, it is a dominant strategy not to invest, and on $\left(y_{01}^{*}, \infty\right)$, it is dominant for a firm with zero capacity to invest if the other holds one unit. The above strategy combination implies that an investment is sure to occur the instant $Y_{t}$ reaches $y_{01}^{*}$ because then $s_{1}^{f}(0,0, y)$ and $s_{1}^{-f}(0,0, y)$ start increasing, while no simultaneous investment can occur at $y_{00}^{p}$ because $s_{1}^{f}\left(0,0, y_{00}^{p}\right)$ and $s_{1}^{-f}\left(0,0, y_{00}^{p}\right)$ are still zero. Once one firm has invested, the other one abstains from investing $\left(s_{1}^{-f}(0, \nu, y)=0\right)$ until $Y_{t}$ reaches $y_{01}^{*}$.

We now show that the above strategy profile is an $M P E$ strategy profile in any subgame starting at $y \in\left[y_{00}^{p}, y_{01}^{*}\right)$. For $y \in\left[y_{00}^{p}, y_{01}^{*}\right)$, if firm $f$ deviates by choosing $s^{\prime}(0,0, y)=0$, the other firm invests at $y$ so that firm $f^{\prime}$ 's dominant strategy in the continuation is to invest at $y_{01}^{*}$ for a continuation payoff of $F^{*}(0,0, y)$. If it chooses to deviate with intensity $s^{\prime}(0,0, y)=\lambda \in(0,1]$, its continuation payoff is:

$$
\frac{\lambda\left[1-s_{1}^{-f}(0,0, y)\right] L(0,0, y)+(1-\lambda) s_{1}^{-f}(0,0, y) F^{*}(0,0, y)+\lambda s_{1}^{-f}(0,0, y) \widetilde{S}(0,0, y)}{\lambda-\lambda s_{1}^{-f}(0,0, y)+s_{1}^{-f}(0,0, y)}
$$

Substituting for $s_{1}^{-f}(0,0, y)$, this is equal to $F^{*}(0,0, y)$. Thus, for any subgame starting at $y \in\left(y_{00}^{p}, y_{01}^{*}\right)$, both firms are indifferent between all possible choices. At $y=y_{00}^{p}$, the continuation payoff from the candidate $M P E$ strategies is $F^{*}\left(0,0, y_{00}^{p}\right)=L\left(0,0, y_{00}^{p}\right)$ as for all possible alternatives. Last, the right partial derivative

\footnotetext{
${ }^{21}$ If the first investor can increase its rent by investing in a second unit, that is if $\Delta L(1,0, y)=\frac{\pi_{20}-\pi_{10}}{r-\alpha} y-I-\left(\frac{y}{y_{01}^{*}}\right) \frac{\pi_{20}-\pi_{10}}{r-\alpha} y$ is positive on some interval $\left[\underline{y_{10}}, \overline{y_{10}}\right]$, then the $M P E$ strategy profile must also specify $s_{1}^{f}(1,0, y)=\left\{\begin{array}{l}1, \\ 0,\end{array}\right.$ $y_{10} \leq \overline{y_{10}}<y_{01}^{*}$. It is tedious, but not difficult, to also work out the corresponding value of $y_{00}^{p}$, which is lower since the rent of the first investor would otherwise exceed that of its opponent. We leave it to interested readers to adapt the foregoing proof to such cases where it might be profitable for the first investor to invest more than once before its opponent does.
} 
$\partial_{y}^{+} s_{1}^{f}\left(0,0, y^{\prime \prime}\right)$ is strictly positive as required by regularity condition $\left(R_{2}\right)$ in Boyer et al. For the proof that there is no other equilibrium outcome, we refer the reader to Fudenberg and Tirole (1985, Appendix 1).

Proof of Proposition 3. See the main text.

Proof of Proposition 4. For each $y \in\left(0, y_{12}^{*}\right], F^{*}(1,1, y), L(1,1, y)$, and $\widetilde{S}(1,1, y)=\frac{\pi_{22}}{r-\alpha} y-I$ are respectively the expected payoffs of becoming the first investor, the second investor, and of investing immediately, simultaneously with the other firm. As in the proof of Proposition 1, it can be shown that the strategy profile defined below is an MPE strategy profile:

$$
\begin{aligned}
& s_{1}^{f}(1,1, y)=s_{1}^{-f}(1,1, y)=\left\{\begin{array}{l}
0, y \in\left[0, y_{11}^{p}\right) \\
\frac{L(1,1, y)-F^{*}(1,1, y)}{L(1,1, y)-\widetilde{S}(1,1, y)}, y \in\left[y_{11}^{p}, y_{12}^{*}\right) . \\
1, y \in\left[y_{12}^{*}, \infty\right)
\end{array}\right. \\
& s_{1}^{f}(1,2, y)=s_{1}^{-f}(1,2, y)=\left\{\begin{array}{l}
0, y \in\left[0, y_{12}^{*}\right) \\
1, y \in\left[y_{12}^{*}, \infty\right)
\end{array}\right. \\
& s_{1}^{f}(2,2, y)=s_{1}^{-f}(2,2, y)=0 \forall y
\end{aligned}
$$

Proof of Proposition 5. 1. Necessity is proven in the main text. To show sufficiency, let $L(1,1, y) \leq$ $S^{*}(1,1, y) \forall y \in\left(0, y_{12}^{*}\right]$. By the definition of $S^{*}(1,1, y)$, one also has $L(1,1, y) \leq S^{*}(1,1, y) \forall y \in\left(0, y_{11}^{s *}\right]$ with $y_{11}^{s *}>y_{12}^{*}$ by (13). We will show that the following (tacit collusion) strategies, whose equilibrium payoff is $S^{*}(1,1, y)$ for both firms, yield an $M P E$ :

$$
\begin{aligned}
& s_{1}^{f}(1,1, y)=s_{1}^{-f}(1,1, y)=\left\{\begin{array}{l}
0, y \in\left[0, y_{11}^{s *}\right) \\
1, y \in\left[y_{11}^{s *}, \infty\right)
\end{array},\right. \\
& s_{1}^{f}(1,2, y)=s_{1}^{-f}(1,2, y)=\left\{\begin{array}{l}
0, y \in\left[0, y_{12}^{*}\right) \\
1, y \in\left[y_{12}^{*}, \infty\right)
\end{array} .\right.
\end{aligned}
$$

For either firm, say $f$, a deviation from $s_{1}^{f}(1,1, y)$ either results in an investment after $y_{11}^{s *}$ is reached, or in an investment before $y_{11}^{s *}$ is reached. In the former instance, since $-f$ has already invested when $f$ invests, the payoff is $F(1,2, y)<F^{*}(1,2, y) \leq S^{*}(1,1, y)$, where the last inequality follows from the fact that $y_{11}^{s}=y_{12}^{*}$ is admissible in the maximization that defines $S^{*}(1,1, y)$. If the deviation results in an investment by $f$ before $y_{11}^{s *}$ is reached, then $-f$ applies $s_{1}^{-f}(1,2, y)$. The payoff to $f$ is $L(1,1, y)$ if the deviation occurs before $y_{12}^{*}$ is reached and $S(1,1, y)$ if it occurs at or after $y_{12}^{*}$ (since in that case $-f$ invests immediately). Since $S(1,1, y) \leq S^{*}(1,1, y)$, the above strategies yield an $M P E$ with joint investment at $y_{11}^{s *}$. This completes the proof that condition $L(1,1, y) \leq$ $S^{*}(1,1, y) \forall y<y_{12}^{*}$ is necessary for existence.

With respect to the existence of a continuum of tacit-collusion $M P E$, suppose now that $S(1,1, y)>L(2,1, y)$ for each $y<y_{12}^{*}$, and define $\underline{y}^{s}$ to be smallest value of $y_{11}^{s} \in\left[y_{12}^{*}, y_{11}^{s *}\right)$ such that:

$$
\frac{\pi_{11}}{r-\alpha} y+\left(\frac{y}{y_{11}^{s}}\right)^{\beta}\left\{\frac{\pi_{22}-\pi_{11}}{r-\alpha} y_{11}^{s}-I\right\} \geq L(2,1, y)
$$

for all $y \in\left[0, y_{12}^{*}\right]$. Then, for any $y_{11}^{s} \in\left[\underline{y}^{s}, y_{11}^{s *}\right]$, one can, as above, construct an MPE such that firms invest jointly at $\tau_{11}^{s}=\inf \left\{t \geq 0 \mid Y_{t} \geq y_{11}^{s}\right\}$. By definition of $y_{11}^{s *}$, the expected payoff from jointly investing at $\tau_{11}^{s}$ is an 
increasing function of the investment trigger $y_{11}^{s}$ over the range $\left[\underline{y}^{s}, y_{11}^{s *}\right]$. It follows that these $M P E$ are Pareto ranked, and that the Pareto optimal $M P E$ corresponds to joint investment at $\tau_{11}^{s *}$.

2. Rents are equal and exceed $F(1,2, y)$ by the definition of $S$. Since the firms act simultaneously, joint profits equal $2 S^{*}(1,1, y)$ under joint investment at $y_{11}^{s *}$.

3. As explained in the text, when $\pi_{22}<\pi_{11}, y_{11}^{s *} \rightarrow \infty$; thus, firms never invest. Otherwise, the above strategy profile implies joint investment at $y_{11}^{s *}$.

Proof of Proposition 6. 3. Assume that $\pi_{22}-\pi_{11}>0$. By Proposition 5.1, a tacit-collusion equilibrium exists if and only if $S^{*}(1,1, y)-L(1,1, y)$ is positive for all $y<y_{12}^{*}$. Thus, we study the sign of:

$$
E(y ; I, \beta) \equiv S^{*}(1,1, y)-L(1,1, y)=-\frac{\pi_{21}-\pi_{11}}{r-\alpha} y+I+K(\beta) y^{\beta}
$$

for $y \in\left[0, y_{12}^{*}\right]$ where, after substitution of the expressions for $y_{12}^{*}$ and $y_{11}^{s *}$,

$$
K(\beta)=\left(\frac{\beta-1}{\beta I}\right)^{\beta-1}\left(\beta^{-1}\left(\frac{\pi_{22}-\pi_{11}}{(r-\alpha)}\right)^{\beta}+\left(\frac{\pi_{12}-\pi_{22}}{r-\alpha}\right)^{\beta}\left(\frac{\pi_{22}-\pi_{21}}{\pi_{22}-\pi_{12}}\right)\right) .
$$

The function $E$ is strictly convex, strictly decreasing in a right neighborhood of zero, and $\lim _{y \rightarrow \infty} E(y ; I, \beta)=\infty$. It follows that $E$ attains its minimum at a unique point $y_{E}>0$ that is characterized by the first-order condition:

$$
\beta K(\beta) y_{E}^{\beta-1}=\frac{\pi_{21}-\pi_{11}}{r-\alpha} .
$$

Substituting in the expression for $E\left(y_{E}\right)$, it follows that the minimized value of $E$ is:

$$
E^{*}(\beta) \equiv \min _{y \geq 0} E(y ; I, \beta)=(1-\beta) K(\beta) y_{E}^{\beta}+I=I-\frac{\beta-1}{\beta} \frac{\pi_{21}-\pi_{11}}{r-\alpha} y_{E} .
$$

Changes in $\sigma$ affect the function $E$ only through $\beta ; \beta$ is a function that is strictly decreasing in $\sigma$ and $\alpha$ (increasing in $r$ ) and that goes to 1 as $\sigma \rightarrow \infty$ and as $\alpha \uparrow r$ (as $r \downarrow \alpha$ ), with $\sigma \geq 0$ and $r>\alpha$. By the envelope theorem, $E^{* \prime}(\beta)<0$. It follows that if $\beta<\beta^{\prime}$ and $E^{*}\left(\beta^{\prime}\right)=0$, then $E^{*}(\beta)>0$, so that $E(y ; I, \beta)>0 \forall y$. Consequently, $\Lambda\left(\beta^{\prime}\right) \subset \Lambda(\beta)$. This proves 3 .

2. Using (15) and (16), the condition for $E^{*}(\beta) \geq 0$ can be written as:

$$
\frac{\pi_{21}-\pi_{11}}{\pi_{22}-\pi_{11}} \leq\left[1+(\beta-1) \frac{\pi_{22}-\pi_{11}}{\pi_{21}-\pi_{11}} \frac{\pi_{21}-\pi_{22}}{\pi_{22}-\pi_{12}}\left(\frac{\pi_{22}-\pi_{12}}{\pi_{22}-\pi_{11}}\right)^{\beta}\right]^{\frac{1}{\beta-1}} .
$$

This is independent of $I$.

1. We show existence by constructing an example. Let $\beta=2$; the condition $E^{*}(2) \geq 0$ can be written, after some manipulations, as:

$$
Q(x)=-x^{2}+b x+c \geq 0,
$$

where $b=\pi_{22}-\pi_{11}, c=\left(\pi_{21}-\pi_{22}\right)\left(\pi_{22}-\pi_{12}\right)$, and $x=\pi_{21}-\pi_{11}$. This quadratic expression is subject to 
features implied by the output competition model, first, under Assumption 1 on demand; and second, under Assumption 3 for the equal-capacity Case 2 under scrutiny. These features are: $\pi_{21}>\pi_{22}>\pi_{11}>\pi_{12}>0$ and $\pi_{21}-\pi_{11}>\pi_{22}-\pi_{12}$, where the last inequality means that the rise in profit from increasing capacity from one to two units is higher when the opponent holds one unit than when it holds two units. Taking $\pi_{21}-\pi_{22}=1$ as normalization, the conditions of the Cournot model are equivalent to:

$$
x>1 ; x>c ; c>b ; b>0 .
$$

For values of $x, b$, and $c$ satisfying conditions (18), $Q(x) \geq 0$ if and only if $x$ is smaller than or equal to the positive root of $Q(x)$, which is equal to $\frac{1}{2}\left(b+\sqrt{b^{2}+4 c}\right)$. This is possible if and only if the positive root is greater than both $c$ and 1 , or:

$$
b \geq \max \{1-c, c-1\} .
$$

Existence of the tacit-collusion $M P E$ when $\beta=2$ is therefore ensured when, in addition to the regular features arising from the Cournot model and under the normalization $\pi_{21}-\pi_{22}=1$,

$$
\pi_{22}-\pi_{11} \geq \max \left\{1-\left(\pi_{22}-\pi_{12}\right),\left(\pi_{22}-\pi_{12}\right)-1\right\}
$$

For example, if $\pi_{21}=1, \pi_{22}=\frac{5}{6}, \pi_{12}=\frac{3}{6}, \pi_{11}=\frac{3.5}{6}$, then $\pi_{21}-\pi_{22}=\frac{1}{6}$; normalizing requires multiplying all those values by 6 ; then $\pi_{22}-\pi_{11}=\frac{9}{6}>\pi_{22}-\pi_{12}-1=1$.

Proof of Lemma 2. We need to show that, if the gain $G(2,1, y)$ from investing immediately for the bigger firm is positive at some value of $y<y_{13}^{*}$, then there exists a value of $y, y_{12}^{p}$ such that $G(2,1, y)<0 \forall y<y_{12}^{p}$. The gain from investing immediately for the bigger firm is

$$
G(2,1, y) \equiv L(2,1, y)-F^{*}(2,1, y)
$$

with

$$
F^{*}(2,1, y)=\left\{\begin{array}{l}
S^{*}(2,2, y) \text { if a collusion episode occurs at }(2,2, y), \\
\frac{\pi_{22}}{r-\alpha} y+\left(\frac{y}{y_{22}^{p}}\right)^{\beta}\left(L\left(2,2, y_{22}^{p}\right)-\frac{\pi_{22}}{r-\alpha} y_{22}^{p}\right) \text { in case of preemption at }(2,2, y)
\end{array}\right.
$$

where $S^{*}(2,2, y)$ and $L(2,2, y)$ correspond to the tacit-collusion and the preemption equilibria analyzed in subsection 3.2 (for $k^{\prime}=2$ ), respectively given by (12) taken at the joint-profit maximizing trigger (13) and by (11).

In order to compute $L(2,1, y)$, first note that, as an implication of Assumption 4, if the bigger firm invests first, it will then have to accommodate whenever the smaller firm introduces a new unit. Consequently, the smaller firm's dominant policy in that case is to acquire two units successively at its stand-alone trigger values:

$$
F^{*}(1,2, y)=\sup _{y_{13}, y_{23}}\left[\frac{\pi_{13}}{r-\alpha} y+\left(\frac{y}{y_{13}}\right)^{\beta}\left(\frac{\pi_{23}-\pi_{13}}{r-\alpha} y_{13}-I\right)+\left(\frac{y}{y_{23}}\right)^{\beta}\left(\frac{\pi_{33}-\pi_{23}}{r-\alpha} y_{23}-I\right)\right],
$$

where $y_{13}^{*}=\frac{1}{\pi_{23}-\pi_{13}}(r-\alpha) I \frac{\beta}{\beta-1}$, and $y_{23}^{*}=\frac{1}{\pi_{33}-\pi_{23}}(r-\alpha) I \frac{\beta}{\beta-1}$ are the corresponding investment triggers. Given the dominant policy of the smaller firm when the bigger firm invests first, the value of the latter, if it 
purchases its third unit at $Y_{t}=y$ when the small firm holds one unit, is:

$$
L(2,1, y)=\frac{\pi_{31}}{r-\alpha} y-I+\left(\frac{y}{y_{13}^{*}}\right)^{\beta} \frac{\pi_{32}-\pi_{31}}{r-\alpha} y_{13}^{*}+\left(\frac{y}{y_{23}^{*}}\right)^{\beta} \frac{\pi_{33}-\pi_{32}}{r-\alpha} y_{23}^{*} .
$$

Use (22) and (20) to compute $G(2,1, y)$ from (19) and use (12) and (13) to express $S^{*}(2,2, y)$ in the resulting expression. Whatever the expression applying in $(20)$, it can be verified that $G(2,1, y)$ is concave and that it is increasing in a right-neighborhood of 0 ; also, $G(2,1,0)=-I$. Consequently, if $G(2,1,0)$ reaches a strictly positive value for some $y<y_{13}^{*}$, then there exists at least one value of $y$ in the interval $\left[0, y_{13}^{*}\right]$, such that $G(2,1, y)=0$. We define $y_{12}^{p}$ as the smallest root and note that $G\left(2,1, y_{22}^{p}\right)$ is increasing, which proves the last statement in the Lemma.

Proof of Proposition 7. The case $0<x^{c}-k^{\prime} \leq 1\left(k^{\prime}=1\right)$ is discussed in the main text; we focus on $1<x^{c}-k^{\prime} \leq 2\left(k^{\prime}=1\right)$ in this proof.

1 and 2. The proof relies on comparing the gain $G(1,2, y)$ for the smaller firm to invest immediately with the gain $G(2,1, y)$ for the bigger firm to do so. $G(2,1, y)$ is given by (19) as described in the proof of Lemma $\mathbf{2}$; $G(1,2, y)$ will be established further below.

\section{Preliminaries.}

Trivially, if $G(2,1, y) \leq 0 \forall y \leq y_{13}^{*}$, investing when its opponent holds one unit is a dominated strategy for the bigger firm. Then the result holds, with the smaller firm investing at its stand-alone date, i.e. when $y$ reaches $y_{12}^{*}$ for the first time. We assume that $G(2,1, y)>0$ for some values of $y \leq y_{13}^{*}$ in the rest of the proof.

The gain from investing immediately for the smaller firm is

$$
G(1,2, y) \equiv L(1,2, y)-F^{*}(1,2, y)
$$

where $F^{*}(1,2, y)$ is given by $(21) . L(1,2, y)$ corresponds to the smaller firm investing first and is given by:

$$
L(1,2, y)=\left\{\begin{array}{l}
S^{*}(2,2, y)-I \text { if a collusion episode occurs at }(2,2, y) \\
\frac{\pi_{22}}{r-\alpha} y+\left(\frac{y}{y_{22}^{p}}\right)^{\beta} L\left(2,2, y_{22}^{p}\right)-I \text { in case of preemption at }(2,2, y)
\end{array}\right.
$$

where $S^{*}(2,2, y)$ and $L(2,2, y)$ apply in case of tacit-collusion and preemption at capacities $(2,2)$ respectively, as analyzed in subsection 3.2 (for $k^{\prime}=2$ ). They are respectively given by (12) taken at the joint-profit maximizing trigger (13) and by (11).

Since tacit collusion yields a higher payoff than preemption at $(2,2)$ by Proposition 5 , it follows that the gain for the smaller firm to invest immediately, if the alternative is the bigger firm taking the lead, is at least equal to the gain in case the preemption episode occurs:

$$
\begin{aligned}
& G(1,2, y) \geq-I+\frac{\pi_{22}}{r-\alpha} y+\left(\frac{y}{y_{22}^{p}}\right)^{\beta}\left(L\left(2,2, y_{22}^{p}\right)-\frac{\pi_{22}}{r-\alpha} y_{22}^{p}\right) \\
& -\sup _{y_{13}, y_{23}}\left[\frac{\pi_{13}}{r-\alpha} y+\left(\frac{y}{y_{13}}\right)^{\beta}\left(\frac{\pi_{23}-\pi_{13}}{r-\alpha} y_{13}-I\right)+\left(\frac{y}{y_{23}}\right)^{\beta}\left(\frac{\pi_{33}-\pi_{23}}{r-\alpha} y_{23}-I\right)\right]
\end{aligned}
$$


Comparing the gains from investing immediately rather than waiting for the smaller versus the bigger firm. An inequality similar to (25), but in the opposite direction, can be obtained in the case of $G(2,1, y)$ by choosing the lower alternative in (20). Substracting it from (25), we have, for $y \leq y_{13}^{*}$,

$$
\begin{aligned}
& G(1,2, y)-G(2,1, y) \geq-I \\
& +\left\{\frac{\pi_{22}}{r-\alpha} y+\left(\frac{y}{y_{22}^{p}}\right)^{\beta}\left(L\left(2,2, y_{22}^{p}\right)-\frac{\pi_{22}}{r-\alpha} y_{22}^{p}\right)\right\} \\
& -\frac{\pi_{13}}{r-\alpha} y-\left(\frac{y}{y_{13}^{*}}\right)^{\beta}\left(\frac{\pi_{23}-\pi_{13}}{r-\alpha} y_{13}^{*}-I\right)-\left(\frac{y}{y_{23}^{*}}\right)^{\beta}\left(\frac{\pi_{33}-\pi_{23}}{r-\alpha} y_{23}^{*}-I\right) \\
& -\frac{\pi_{31}}{r-\alpha} y+I-\left(\frac{y}{y_{13}^{*}}\right)^{\beta}\left(\frac{\pi_{32}-\pi_{31}}{r-\alpha} y_{13}^{*}\right)-\left(\frac{y}{y_{23}^{*}}\right)^{\beta} \frac{\pi_{33}-\pi_{32}}{r-\alpha} y_{23}^{*} \\
& +\left\{\frac{\pi_{22}}{r-\alpha} y+\left(\frac{y}{y_{22}^{p}}\right)^{\beta}\left(L\left(2,2, y_{22}^{p}\right)-\frac{\pi_{22}}{r-\alpha} y_{22}^{p}\right)\right\} .
\end{aligned}
$$

Substituting for $L\left(2,2, y_{22}^{p}\right)=\frac{\pi_{32}}{r-\alpha} y_{22}^{p}-I+\left(\frac{y}{y_{23}^{*}}\right)^{\beta} \frac{\pi_{33}-\pi_{32}}{r-\alpha} y_{23}^{*}$ and simplifying gives

$$
\begin{aligned}
G(1,2, y)-G(2,1, y) \geq 2\left(\frac{y}{y_{22}^{p}}\right)^{\beta} & \frac{\pi_{32}-\pi_{22}}{r-\alpha} y_{22}^{p} \\
& -\left(\frac{y}{y_{13}^{*}}\right)^{\beta}\left(\frac{\pi_{23}-\pi_{13}-\pi_{32}+\pi_{31}}{r-\alpha} y_{13}^{*}-I\right)-\left(\frac{y}{y_{23}^{*}}\right)^{\beta}\left(\frac{\pi_{32}-\pi_{23}}{r-\alpha} y_{23}^{*}-I\right) .
\end{aligned}
$$

Evaluating the $\pi_{i j}$ as price times quantity where this helps sign an expression, with $p_{l}$ defined as the industry price when there are $l=i+j$ capacity units in the industry, this can be written as:

$$
\begin{aligned}
& G(1,2, y)-G(2,1, y) \geq \\
& \left(\frac{y}{y_{22}^{p}}\right)^{\beta}\left[\frac{6 p_{5}-4 p_{4}}{r-\alpha} y_{22}^{p}-2 I-\left(\frac{y_{22}^{p}}{y_{13}^{*}}\right)^{\beta}\left(\frac{5 p_{5}-4 p_{4}}{r-\alpha} y_{13}^{*}-I\right)-\left(\frac{y_{22}^{p}}{y_{23}^{*}}\right)^{\beta}\left(\frac{p_{5}}{r-\alpha} y_{23}^{*}-I\right)\right]
\end{aligned}
$$

This shows that the difference in gains is higher than the product of the positive function $\left(\frac{y}{y_{22}^{p}}\right)^{\beta}$ by a function $\delta$ of three variables evaluated respectively at the trigger values $y_{22}^{p}, y_{13}^{*}$, and $y_{23}^{*}$ :

$$
\begin{aligned}
& \delta\left(y_{22}, y_{13}, y_{23}\right) \\
= & \frac{6 p_{5}-4 p_{4}}{r-\alpha} y_{22}-2 I-\left(\frac{y_{22}}{y_{13}}\right)^{\beta}\left(\frac{5 p_{5}-4 p_{4}}{r-\alpha} y_{13}-I\right)-\left(\frac{y_{22}}{y_{23}}\right)^{\beta}\left(\frac{p_{5}}{r-\alpha} y_{23}-I\right)
\end{aligned}
$$

We are going to show that $\delta\left(y_{22}^{p}, y_{13}^{*}, y_{23}^{*}\right)$ is positive. Given $y_{13}=y_{13}^{*}$, let us treat $y_{22}$ and $y_{23}$ as variables and let us note that $\delta\left(y_{22}, y_{13}, y_{23}\right)$ is zero if $y_{13}^{*}=y_{23}=y_{22}$. First we show that $y_{13}^{*}<y_{22}^{p}<y_{23}^{*}$. Because $y_{22}^{p}$ is a preemption trigger, it is by definition lower than the corresponding stand-alone trigger $y_{22}^{*}$ $=\arg \max _{y_{22}}\left\{\frac{\pi_{22}}{r-\alpha} y+\left(\frac{y}{y_{22}}\right)^{\beta}\left(\frac{\pi_{32}-\pi_{22}}{r-\alpha} y_{22}-I\right)+\left(\frac{y}{y_{32}}\right)^{\beta} \frac{\pi_{33}-\pi_{32}}{r-\alpha} y_{32}\right\}=\frac{1}{\pi_{32}-\pi_{22}}(r-\alpha) I \frac{\beta}{\beta-1}$. The inequality $y_{22}^{p}<y_{23}^{*}$ follows from the observation that $y_{22}^{*}<y_{23}^{*}$. The inequality $y_{13}^{*}<y_{22}^{p}$ stems from the following argument. Suppose the investor at $y_{22}^{p}$ ignored the cannibalism effect, the impact of introducing a new capacity unit 
on the revenue from its existing unit, effectively treating its existing unit as an independent existing firm. This is feasible and the corresponding payoff is thus reachable. In fact it corresponds to the problem that defines $y_{13}^{*}$. Consequently $y_{13}^{*} \leq y_{22}^{p}$; equality would occur if the preemption episode at $y_{22}^{p}$ did not leave any rent to the first investor. However, by Proposition 2, rents are equalized but strictly positive; this requires $y_{13}^{*}<y_{22}^{p}$.

Second we note that $\frac{\partial \delta}{\partial y_{22}}>0$ and we show $\frac{\partial \delta}{\partial y_{23}}>0$ for $y_{23} \in\left[y_{13}^{*}, y_{23}^{*}\right]$, which implies, given that $\delta\left(y_{13}^{*}, y_{13}^{*}, y_{13}^{*}\right)=$ 0 and given $y_{13}^{*}<y_{22}^{p}<y_{23}^{*}$, that $\delta\left(y_{22}^{p}, y_{13}^{*}, y_{23}^{*}\right)>0$. Standard computations show that $\frac{\partial \delta\left(y_{22}^{p}, y_{13}^{*}, y_{23}^{*}\right)}{\partial y_{23}}=$ $\left(y_{22}\right)^{\beta}\left[(\beta-1) \frac{p_{5}}{r-\alpha}\left(y_{23}^{*}\right)^{-\beta}-\beta\left(y_{23}^{*}\right)^{-(\beta+1)}\right]$. Substituting $y_{23}^{*}$, with $\pi_{23}=2 p_{5}$ and $\pi_{33}=3 p_{6}$, it follows that $\frac{\partial \delta\left(y_{22}^{p}, y_{13}^{*}, y_{23}^{*}\right)}{\partial y_{23}}$ is proportional to $\left(\frac{p_{5}}{3 p_{6}-2 p_{5}}-1\right)$ which is positive since $p_{5}>p_{6}$. Thus $\frac{\partial \delta}{\partial y_{23}}>0$ for $y_{23}=y_{23}^{*}$ and for any lower value of $y_{23}$. This completes the proof that $G(1,2, y)-G(2,1, y)>0 \quad \forall y<y_{13}^{*}$.

Preemption in MPE. At levels of $y$ such that $G(2,1, y)<0$, investing is a dominated strategy for the bigger firm, and the best response for the smaller firm is to wait until $G(1,2, y)$ reaches a maximum if that maximum is reached when $G(2,1, y)<0$. For any $y$ such that $G(2,1, y) \geq 0, G(1,2, y)>0$, so the best response for the small firm to a strategy by the bigger firm of investing at such level of $Y_{t}$ is to preempt at $y-\varepsilon$. Precisely, by Lemma $2, G\left(2,1, y_{12}^{p}\right)=0$. Since $G(1,2, y)-G(2,1, y)>0$, it follows that $G\left(1,2, y_{12}^{p}\right)>0$. Then, the smaller firm should invest at $y_{12}^{p}$ which is achieved in equilibrium for the following strategies:

$$
s_{1}(1,2, y)=\left\{\begin{array}{l}
0, \text { if } y \in\left[0, y_{12}^{p}\right) \\
1, \text { if } y \in\left[y_{12}^{p}, \infty\right)
\end{array} \quad ; s_{1}(2,1, y)=\left\{\begin{array}{l}
0, \text { if } y \in\left[0, y_{12}^{p}\right) \\
\frac{L(2,1, y)-F^{*}(2,1, y)}{L(2,1, y)-S(2,1, y)}, \text { if } y \in\left[y_{12}^{p}, y_{12}^{*}\right) \\
1, \text { if } y \in\left[y_{12}^{*}, \infty\right)
\end{array}\right.\right.
$$

By Lemma $2, G\left(2,1, y_{12}^{p}\right)=0$. Since $G(1,2, y)-G(2,1, y)>0$, it follows that $G\left(1,2, y_{12}^{p}\right)>0$. Then, the smaller firm should invest at $y_{12}^{p}$ which is achieved in equilibrium for the following strategies:

$$
s_{1}(1,2, y)=\left\{\begin{array}{l}
0, \text { if } y \in\left[0, y_{12}^{p}\right) \\
1, \text { if } y \in\left[y_{12}^{p}, \infty\right)
\end{array} \quad ; s_{1}(2,1, y)=\left\{\begin{array}{l}
0, \text { if } y \in\left[0, y_{12}^{p}\right) \\
\frac{L(2,1, y)-F^{*}(2,1, y)}{L(2,1, y)-S(2,1, y)}, \text { if } y \in\left[y_{12}^{p}, y_{12}^{*}\right) \\
1, \text { if } y \in\left[y_{12}^{*}, \infty\right)
\end{array}\right.\right.
$$

Note that the smaller firm invests first with probability one. Consequently, a preemption episode at $\left(k, k^{\prime}\right)$ with the bigger firm as first investor cannot exist in $M P E$.

3 can be readily verified.

Proof of Proposition 8. Under Assumption 4 with $k^{\prime}=1$ :

1. If $\pi_{32}-\pi_{22}=0$, there exists no value of $Y_{t}$ at which it is profitable for the bigger firm to invest if the smaller does so; thus, there exists no tacit-collusion $M P E$ with simultaneous investment. Since $\pi_{22}>\pi_{12}$, abstaining from investing is a dominated strategy for the smaller firm; thus, there exists no tacit-collusion $M P E$ by inaction.

2. $\pi_{32}-\pi_{22}>0$. The sole alternative to the tacit-collusion $M P E$, if it exists, is the preemption $M P E$. The proof is similar to that of Proposition 5 so we only introduce the main elements. By Proposition 7, for the bigger firm, the alternative to tacit collusion is to be passive in the preemption $M P E$; for the smaller firm, the alternative to 
tacit collusion is to be first investor in the preemption $M P E$. Consequently, adapting Proposition 5, collusion is an $M P E$ if and only if $S(2,1, y)-F^{*}(2,1, y) \geq 0$ and $S(1,2, y)-L(1,2, y) \geq 0$ for all $y \leq y_{21}^{s}$, where $y_{21}^{s}$ is the threshold at which both firms invest simultaneously. We compute these gains from tacit collusion.

First, we evaluate $S(2,1, y)$ and $S(1,2, y)$. Since $\pi_{32}-\pi_{22}>0,2<x^{c} \leq 3$, so that a capacity of three units is necessary to produce the unconstrained Cournot output. In case of simultaneous investment, both firms acquire one unit at some common trigger $y_{21}^{s}$ to be defined. Then the bigger firm holds three units and must accommodate any increase in production up to $x^{c}$ by the smaller firm. Thus, it is a dominant strategy for the latter to acquire a third unit at its stand-alone threshold $y_{23}^{*}$, if $y_{21}^{s} \leq y_{23}^{*}$, or at $y_{23}=y_{21}^{s}$ if $y_{21}^{s}>y_{23}^{*}$. Once both firms hold three units each, the game is over by Proposition $1(\mathrm{~A})$. Thus, the tacit-collusion equilibrium, if it exists, involves simultaneous investment at $y_{21}^{s}$, followed, possibly immediately, by an investment by the smaller firm. The corresponding values for the bigger and the smaller firms are respectively:

$$
\begin{aligned}
& S(2,1, y)=\frac{\pi_{21}}{r-\alpha} y+\left(\frac{y}{y_{21}^{s}}\right)^{\beta}\left(\frac{\pi_{32}-\pi_{21}}{r-\alpha} y_{21}^{s}-I\right)+\left(\frac{y}{y_{23}}\right)^{\beta} \frac{\pi_{33}-\pi_{32}}{r-\alpha} y_{23} \\
& S(1,2, y)=\frac{\pi_{12}}{r-\alpha} y+\left(\frac{y}{y_{21}^{s}}\right)^{\beta}\left(\frac{\pi_{23}-\pi_{12}}{r-\alpha} y_{21}^{s}-I\right)+\left(\frac{y}{y_{23}}\right)^{\beta}\left(\frac{\pi_{33}-\pi_{23}}{r-\alpha} y_{23}-I\right),
\end{aligned}
$$

where either $y_{23}=y_{23}^{*}>y_{21}^{s}$ or $y_{21}^{s}=y_{23} \geq y_{23}^{*} .{ }^{22}$ We now evaluate the gain from colluding for the bigger firm, over its alternative of letting the smaller firm invest first, using $(20)$ for $F^{*}(2,1, y)$ :

$$
\begin{aligned}
G S(2,1, y)= & S(2,1, y)-F^{*}(2,1, y) \\
= & \frac{\pi_{21}}{r-\alpha} y+\left(\frac{y}{y_{21}^{s}}\right)^{\beta}\left(\frac{\pi_{32}-\pi_{21}}{r-\alpha} y_{21}^{s}-I\right)+\left(\frac{y}{y_{23}}\right)^{\beta} \frac{\pi_{33}-\pi_{32}}{r-\alpha} y_{23} \\
& -\max \left\{S^{*}(2,2, y), \frac{\pi_{22}}{r-\alpha} y+\left(\frac{y}{y_{22}^{p}}\right)^{\beta}\left(L\left(2,2, y_{22}^{p}\right)-\frac{\pi_{22}}{r-\alpha} y_{22}^{p}\right)\right\} .
\end{aligned}
$$

Similarly, we evaluate the gain from colluding for the smaller firm, over its alternative of investing first, using (24) for $L(1,2, y)$ :

$$
\begin{aligned}
G S(1,2, y)= & S(1,2, y)-L(1,2, y) \\
= & \frac{\pi_{12}}{r-\alpha} y+\left(\frac{y}{y_{21}^{s}}\right)^{\beta}\left(\frac{\pi_{23}-\pi_{12}}{r-\alpha} y_{21}^{s}-I\right)+\left(\frac{y}{y_{23}}\right)^{\beta}\left(\frac{\pi_{33}-\pi_{23}}{r-\alpha} y_{23}-I\right) \\
& +I-\max \left\{S^{*}(2,2, y), \frac{\pi_{22}}{r-\alpha} y+\left(\frac{y}{y_{22}^{p}}\right)^{\beta}\left(L\left(2,2, y_{22}^{p}\right)-\frac{\pi_{22}}{r-\alpha} y_{22}^{p}\right)\right\} .
\end{aligned}
$$

Let $y_{12}^{s *}$ and $y_{21}^{s *}$ be the values of $y$ that maximize $S(1,2, y)$ and $S(2,1, y)$ respectively with respect to $y_{21}^{s}$. That is, $y_{12}^{s *}=\frac{1}{\pi_{23}-\pi_{12}}(r-\alpha) I \frac{\beta}{\beta-1} ; y_{21}^{s *}=\frac{1}{\pi_{32}-\pi_{21}}(r-\alpha) I \frac{\beta}{\beta-1}$. Note that $y_{12}^{s *}<y_{21}^{s *}$. Consider $y_{12}^{s *}$ and $y_{21}^{s *}$ as possible triggers in a tacit-collusion equilibrium; since $S(1,2, y)$ is decreasing in $y$ beyond its maximum, it is a dominant strategy for the smaller firm to invest when $y \geq y_{12}^{s *}$. Thus, in $M P E, y_{12}^{s} \leq y_{12}^{s *}$ and simultaneous investment at $y_{12}^{s *}$ yields a higher payoff to both firms than at $y_{12}^{s}<y_{12}^{s *}$. This equilibrium exists if and only if both $S(1,2, y)-L(1,2, y)$ and $S(2,1, y)-F^{*}(2,1, y)$ are nonnegative for any $y \leq y_{12}^{s *}=y_{23}$. The rest of the proof of 2 , about parameter conditions, is otherwise similar to that of Proposition 6.

\footnotetext{
${ }^{22}$ We take the case $y_{23}=y_{21}^{s}$ corresponding to situations where $y_{23}^{*}<y_{21}^{s}$ : the second investment of the smaller firm occurs later under the tacit-collusion trigger than under the stand-alone trigger $y_{23}^{*}$ because the smaller firm delays its first investment beyond $y_{23}^{*}$ in order to collude. The approach is identical for the alternative case and leads to the same implications.
} 
3. Let us show that the value that maximizes $S(1,2, y)+S(2,1, y)$ is higher than $\min \left(y_{12}^{s *}, y_{21}^{s *}\right)$. Since $y_{12}^{s *}$ maximizes $S(1,2, y), \frac{\partial S\left(1,2, y_{12}^{s *}\right)}{\partial y}=0$ while, since $y_{12}^{s}<y_{12}^{s *}, S(2,1, y)$ is rising in $y$ at $y=y_{12}^{s *}$. It follows that $S\left(1,2, y_{12}^{s *}\right)+S\left(2,1, y_{12}^{s *}\right)$ is rising in $y$, so that its maximum at some value $y_{12}^{s * *}$ strictly above $y_{12}^{s *}$. However, at any $y>y_{12}^{s *}$, it is a dominant strategy for the smaller firm to invest, so that joint investment at $y_{12}^{s * *}$ cannot occur in $M P E$.

\section{REFERENCES}

[1] Allen, B., Deneckere, R., Faith, T. and D. Kovenock (2000), "Capacity precommitment as a barrier to entry: A Bertrand-Edgeworth approach," Economic Theory 15, 501-530.

[2] Arrow, K.J. and A.C. Fisher (1974), "Environmental Preservation, Uncertainty, and Irreversibility," Quarterly Journal of Economics, 88(2), 312-319.

[3] Athey, S. and A. Schmutzler (2001), "Investment and Market Dominance," Rand Journal of Economics, 32(1), 1-26.

[4] Baldursson, F.M. (1998), "Irreversible investment under uncertainty in oligopoly," Journal of Economic Dynamics and Control, 22, 627-644.

[5] Bayer, C. (2007), "Investment timing and predatory behavior in a duopoly with endogenous exit," Journal of Economic Dynamics and Control, 31(9), 3069-3109.

[6] Besanko, D. and U. Doraszelski (2004), "Capacity dynamics and endogenous asymmetries in firm size," Rand Journal of Economics, 35(1), 23-49.

[7] Besanko, D. , U. Doraszelski, L. Xiaoyuan Lu and M. Satterthwaite (2010), "Lumpy capacity investment and disinvestment dynamics," Operations Research, forthcoming.

[8] Boyer, M., Lasserre, P., Mariotti, T. and M. Moreaux (2001), "Real Options, Preemption, and the Dynamics of Industry Investments," CIRANO WP 2001s-64.

[9] Boyer, M., Lasserre, P., Mariotti, T. and M. Moreaux, (2004) "Preemption and Rent Dissipation under Bertrand Competition," International Journal of Industrial Organization, 22(3), 309-28.

[10] Boyer, M., Gravel, E. and P. Lasserre (2011), "Real Options and Strategic Competition: A Survey of the Different Modeling Strategies," CIRANO WP (forthcoming).

[11] Chevalier-Roignant, B. and L. Trigeorgis (2010), Competitive Strategy: Options and Games, forthcoming.

[12] Décamps, J.-P. and T. Mariotti (2004), "Investment Timing and Learning Externalities," Journal of Economic Theory, 118(1), 80-102.

[13] Deneckere, R.J. and D.Kovenock (1996), "Bertrand-Edgeworth duopoly with unit cost asymmetry," Economic Theory 8(1), 1-25.

[14] Dixit, A (1980), "The role of investment in entry deterrence," Economic Journal 90, 95-106.

[15] Dixit, A.K. and R.S. Pindyck (1994), Investment under Uncertainty, Princeton University Press, Princeton.

[16] Doraszelski, U. (2004), "Innovations, Improvements, and the Optimal Adoption of New Technologies," Journal of Economic Dynamics and Control, 28(7), 1461-80. 
[17] Dutta, P.K. (1995a), "A Folk Theorem for Dynamic Games", Journal of Economic Theory 66, 1-32.

[18] Dutta, P.K. (1995b), "Collusion, Discounting and Dynamic Games", Journal of Economic Theory 66, 289306.

[19] Fudenberg, D., R. Gilbert, J. Stiglitz and J. Tirole (1983), "Preemption, Leapfrogging, and Competition in Patent Races," European Economic Review 22, 3-31.

[20] Fudenberg, D. and J. Tirole (1983), "Capital as a Commitment: Strategic Investment to Deter Mobility," Journal of Economic Theory 31, 227-250.

[21] Fudenberg, D. and J. Tirole (1985), "Preemption and Rent Equalization in the Adoption of New Technology," Review of Economic Studies 52, 383-401.

[22] Fudenberg, D. and J. Tirole (1987), "Understanding Rent Dissipation: On the Use of Game Theory in Industrial Organization," American Economic Review 77, 176-83.

[23] Genc, T., S.S. Reynolds and S. Sen (2007), "Dynamic Oligopolistic Games Under Uncertainty: A Stochastic Programming Approach," Journal of Economic Dynamic and Control,31, 55-80.

[24] Gilbert, R.J. and R.G. Harris (1984), "Competition with Lumpy Investment," Rand Journal of Economics 15, 197-212.

[25] Grenadier S. (1996), "The Strategic Exercise of Options: Development Cascades and Overbuilding in Real Estate Markets," Journal of Finance 51(5), 1653-1679.

[26] Grenadier S. (2002), "Option Exercise Games: An Application to the Equilibrium Investment Strategies of Firms," The Review of Financial Studies 15(3), 691-721.

[27] Harrison, M. J. (1985), Brownian Motion and Stochastic Flow Systems, John Wiley and Sons, New York.

[28] Harris, C. J. and J. S. Vickers (1985), "Patent Races and the Persistence of Monopoly," Journal of Industrial Economics 33(4), 461-81.

[29] Haurie, A. and G. Zaccour (2005), "S-Adapted Equilibria in Games Played over Event Trees: An Overview," Annals of International Society of Dynamic Games 7, 367-400.

[30] Henry, C. (1974), "Investment Decision under Uncertainty: The Irreversibility Effect," American Economic Review 64(6), 1006-1012.

[31] Huisman, K.J.M. (2001), Technology Investment: A Game Theoretic Real Option Approach, Kluwer Academic Publishers, Norwell.

[32] Huisman, K.J.M. and P.M. Kort (2003), "Strategic technology adoption taking into account future technological improvements: A real options approach," European Journal of Operational Research 144(1), 209-33.

[33] Kreps, D.M. and J.A. Scheinkman (1983), "Quantity precommitment and Bertrand competition yield Cournot outcomes," Bell Journal of Economics 14(2), 326-337.

[34] Lambrecht, B. and W. Perraudin (2003), "Real Options and Preemption under Incomplete Information," Journal of Economic Dynamics and Control 27(4), 619-43.

[35] Leahy, J.V. (1994), "Investment in Competitive Equilibrium: The Optimality of Myopic Behavior," Quarterly Journal of Economics CIV, 1105-1133. 
[36] Mason, R. and H. Weeds (2005), "Can Greater Uncertainty Hasten Investments?," DP, http://eprints.soton.ac.uk/33429/01/nop15.pdf.

[37] Mills, D. (1988), "Preemptive Investment Timing," Rand Journal of Economics 19(1), 114-22.

[38] Nocke, V. (2007), "Collusion and dynamic (under-) investment in quality," Rand Journal of Economics 38 (1) , 227-49.

[39] Pawlina, G. and P. M. Kort (2006), "Real Options in an Asymmetric Duopoly: Who Benefits from Your Competitive Disadvantage?," Journal of Economics and Management Strategy 15(1), 1-35.

[40] Posner, R.A. (1975), "The social costs of monopoly and regulation," Journal of Political Economy 83, 807-27.

[41] Smets, F. (1995), "Exporting versus Foreign Direct Investment: The Effect of Uncertainty, Irreversibilities, and Strategic Interactions," Bank for International Settlements Working Paper, Basel, Switzerland.

[42] Smit J.T.J. and L. Trigeorgis (2004), Strategic Investment: Real Options and Games, Princeton University Press, Princeton.

[43] Spence, A.M. (1979), "Entry, capacity, investment and oligopolistic pricing," Bell Journal of Economics 19(1), 534-544.

[44] Stiglitz, R. and P. Dasgupta (1988), "Potential Competition, Actual Competition, and Economic Welfare," European Economic Review 33(2-3), 569-77.

[45] Vives, X., (1999), Oligopoly Pricing: Old Ideas and New Tools, MIT Press, Cambridge.

[46] Weeds, H. (2002), "Strategic Delay in a Real Options Model of R\&D Competition," Review of Economic Studies 69 (3), 729-47. 